\title{
Revision of the genus Sinopoda Jäger, 1999 in Laos with discovery of the first eyeless huntsman spider species (Sparassidae: Heteropodinae)
}

\author{
PETER JÄGER
}

Arachnology, Senckenberg Research Institute, Arachnology, Senckenberganlage 25, 60325 Frankfurt am Main, Germany. E-mail: peter.jaeger@senckenberg.de

\begin{abstract}
The genus Sinopoda Jäger, 1999 is recorded for the first time in Laos. Nine new species are described: Sinopoda steineri spec. nov. (female; Luang Nam Tha), S. tham spec. nov. (male, female; Oudomxai), S. sitkao spec. nov. (female; Luang Prabang), S. taa spec. nov. (female; Luang Prabang), S. suang spec. nov. (female; Huaphan), S. peet spec. nov. (female; Huaphan), S. guap spec. nov. (female; Khammuan), S. soong spec. nov. (female; Khammuan), S. scurion spec. nov. (female; Khammuan). All species have been collected from caves. Sinopoda scurion spec. nov. represents the first record of an eyeless huntsman spider, $S$. guap spec. nov. exhibits only small lenses of six eyes (AME lacking), S. soong spec. nov. has only two small eye lenses. Four immature individuals (Sinopoda sp. indet. A-D) exhibited a reduced size or number of eyes, they are listed including their localities although they could not be identified to species level.
\end{abstract}

Key words: taxonomy, systematics, new species, troglomorphy

\section{Introduction}

The spider genus Sinopoda Jäger, 1999 is distributed in East Asia and in the northern parts of South East Asia with 40 species described so far, 31 of which are known from China (Jäger 1999, Platnick 2012). Representatives live in humid habitats in leaf litter, on tree bark and grass, in rock crevices and in caves (Jäger 1998, 1999; Liu et al. 2008; Zhang et al. 2007). Liu et al. (2008) reviewed briefly Sparassidae occurring in caves. The authors listed twelve species reported from caves, nine species of the genus Heteropoda Latreille, 1804, and one each of the genera Berlandia Lessert, 1921, Sinopoda and Spariolenus Simon, 1880. Moreover, they described nine new Sinopoda species, all occurring in caves in southern China. Bayer and Jäger (2009) recorded two new and one described species of the genus Heteropoda from Laos (H. aemulans, H. steineri, as well as H. maxima Jäger, 2001), whose occurrence is apparently restricted to caves, whereas another species H. simplex Jäger and Ono, 2000 occurred in caves and also humid habitats outside of caves. Moradmand and Jäger (2011) described four Spariolenus species from Iran, two of them collected in caves, the other two from crevices near river banks. All 25 cave-dwelling Sparassidae have their eyes with developed lenses and pigments, only in rare cases body and leg pigmentation is reduced (e.g., in Sinopoda semicirculata Liu et al., 2008). The strongest eye (size) reduction known so far occurred in Heteropoda steineri Bayer and Jäger, 2009 from the Xe Bang Fai cave in Khammuan Province in Laos, and in Sinopoda microphthalma (Fage, 1929) from Batu caves in Malaysia. All cave-dwelling Sparassidae but Berlandia tenebricola Simon and Fage, 1922 belong clearly to the subfamily Heteropodinae, whose representatives generally prefer humid habitats like forests or stream valleys (Jäger 2001, unpubl. data). Berlandia was assumed to be related to the Heteropodinae genus Spariolenus (Jäger 2004).

The first completely eyeless species of huntsman spiders described in the present paper exhibit neither eye lenses nor any pigments. It occurs in a cave system 100 kilometres west of Xe Bang Fai cave. From this larger Khammuan region other cave-dwellers with striking adaptations have been recorded (Lourenço 2007, 2012; Kottelat \& Steiner 2010; Yeo \& Ng 1999): the scorpions Troglokhammouanus steineri Lourenço, 2007 (in Xe Bang Fai cave) and Vietbocap lao Lourenço, 2012 (in Nam Lot cave), a blind cave fish, Bangana musaei Kottelat and Steiner, 2010 (Grotte des Nuages, Xe Bangfai cave system), and a yet undescribed freshwater crab of the 
monotypic genus Erebusa Yeo and Ng, 1999 (Brandis, personal communication; same locality as the eyeless Sinopoda scurion spec. nov.). In the type locality of S. scurion spec. nov. no other Sparassidae or another similarly large spider species have been observed. Small Diplopoda, tiny Telemidae, and the large Typopeltis magnificus were recorded, among others. Practically nothing is known about the biology or ecology of the new Sinopoda species.

Material was either collected by the author or material collected on cave expeditions by other persons was trusted to the author. From this material, nine Sinopoda species appeared to be new to science. All of them have been recorded exclusively from caves, some of which have been extensively surveyed and described: Tham Nam Eng in Dreybrodt and Laumanns (2005, 2008), Tham Na Thong, Tham Mokfek, and Tham Luang in Dreybrodt and Laumanns (2010), Tham Chom Ong in Dreybrodt and Laumanns (2010, 2011), and Tham Nguen in Dreybrodt and Laumanns (2005). The genus Sinopoda is recorded from Laos for the first time.

Since cave adaptations and troglomorphic features are a serious issue in this genus in contrast to other genera of this subfamily (Heteropodinae), four specimens showing reduction or even loss of eyes are included, although they are immature and could not be identified to species level. Moreover, the description of the new species with their gradually increasing troglomorphic features may be useful for potential nature conservation issues concerning caves (Paquin \& Dupérré 2009 and references therein) considering that limestone caves in Laos are an important (eco-)touristic target.

\section{Material and methods}

Measurements are in millimetres, arising points of tegular appendages are given as clock-position of the unexpanded left palp in ventral view. Epigynes are dissected and treated with $96 \%$ lactic acid in order to recognise internal details of the internal duct system. When removing tissue around the internal duct system usually the membranous part between fertilisation ducts is also removed in order to recognise all details of structures situated ventrally to this membrane (Fig. 20). In Sinopoda tham spec. nov. for instance this membranous structure was detected to be an expandable sac (Figs 19,23), in which most likely the male dRTA is fixed during copulation (according to unpublished observations in copulating Sinopoda spiders). Terminology originally used by Jäger (1999) was subsequently partly modified: ledges of epigynum = epigynal pockets; head of spermathecae = glandular appendages. Epigynal pockets are interpreted as structures guiding male palpal parts (embolus plus apophysis) during the copulation. The copulatory opening is situated on the medio-anterior end of the pockets. The narrow part between the copulatory openings is named "lobal septum", a median septum as defined in other Heteropodinae is absent. In some species furrows anterior to the epigynal pockets occur, which are named here "lateral furrows". They can have different orientation and lengths. The length of the epigynal field includes the anterior bands. Cheliceral teeth have always median largest in the anterior row and three sub-equal and a small one in the posterior row (Figs 74, 80). Leg and palp measurements are given as: total (femur, patella, tibia, metatarsus, tarsus). Spination pattern given is following Davies (1994): sums of all spines are listed (prolateral, dorsal, retrolateral, ventral), when ventral spines are absent only three digits are listed. Leg formula is given as order of legs according to their length (femur to tarsus) in Arabic numbers. Size classes are used according to Jäger (2001: 14): small $(<10 \mathrm{~mm})$, medium $(>10$ and $<20 \mathrm{~mm})$, large $(>20$ and $<30 \mathrm{~mm})$, very large $(>30 \mathrm{~mm})$. Material is stored in $70 \%$ denatured ethanol. Photos are taken by the author, exceptions are indicated in legends.

Females of Sinopoda steineri spec. nov., S. tham spec. nov., S. suang spec. nov., S. peet spec. nov. as well as the Chinese species S. triangula Liu et al., 2008 showed similar external and internal structures of their copulatory organs. The same is true for S. sitkao spec. nov. and the Chinese S. undata Liu et al., 2008 as well as for the Laotian species $S$. taa spec. nov. and the Chinese $S$. fornicata Liu et al., 2008. Since only females of all but one species are known from Laos, no phylogenetic implications such as the erection of species groups are considered here. In differential diagnoses characters are listed for identification purpose only, species are listed according to their provincial distribution from North to South (see Fig. 81). Altitudes were received from Google Earth and are added in square brackets.

Abbreviations: ALE-anterior lateral eyes, AME-anterior median eyes, AW-anterior width of dorsal shield of prosoma, dRTA—dorsal branch of RTA, OL—opisthosoma length, OW—opisthosoma width, PJ—serial number of Sparassidae examined by Peter Jäger, PL—length of dorsal shield of prosoma, PLE—posterior lateral 
eyes, PME—-posterior median eyes, PW—width of dorsal shield of prosoma, RTA — retrolateral tibial apophysis, SD—serial number of tissue samples for molecular analyses, vRTA—ventral branch of RTA, I-IV_legs I to IV.

Museum collections: SMF—Senckenberg Research Institute, Frankfurt (Peter Jäger).

\section{Taxonomy}

\section{Sparassidae Bertkau, 1872}

\section{Heteropodinae Thorell, 1873}

\section{Sinopoda Jäger, 1999}

\section{Sinopoda steineri spec. nov.}

Figs 1-5, 81

Type material. Holotype: female, LAOS: Luang Nam Tha Province: Tham Nam Eng, N 2043'25.5", E $101^{\circ} 9^{\prime} 18.6^{\prime \prime}$ [730 $\mathrm{m}$ altitude], cave in limestone, by hand, 9 February 2005, H. Steiner leg., field number of H. Steiner 091/05 (SMF, PJ 3383).

Diagnosis. Medium-sized Heteropodinae, body length of female: 12.7. Female (Figs 1-3) intermediate between those of $S$. taa spec. nov. and $S$. tham spec. nov. in respect to the shape of epigynal pockets, orientation of lateral furrows, and the shape of the internal duct system, but can be distinguished from females of those species by 1. Parallel part of internal duct system similarly long as in $S$. tham spec. nov. (longer than in $S$. taa spec. nov.), but with width at glandular appendages wider than at posterior part (reverse in S. tham spec. nov.), 2. Lobal septum and epigynal pockets forming an anchor (triangle in $S$. taa spec. nov., broad reverse "T" in $S$. tham spec. nov.), 3. Lateral furrows long, reaching lateral margins of lateral lobes and running diagonally (mostly longitudinal in $S$. tham spec. nov., transversal in $S$. taa spec. nov.).

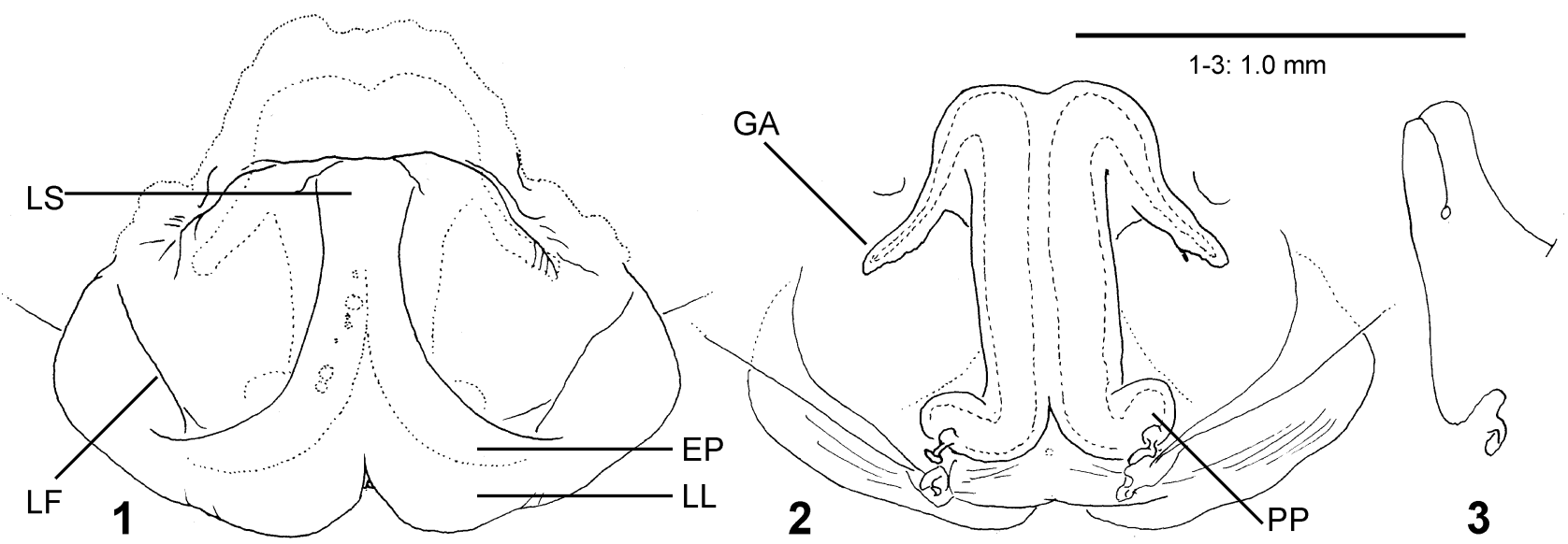

FIGURES 1-3. Sinopoda steineri spec. nov., holotype female from Ban Nam Eng, Luang Nam Tha, copulatory organ. 1 Epigyne, ventral; 2 Vulva, dorsal; 3 Schematic course of internal duct system, dorsal. EP—epigynal pockets, GA—glandular appendage, LF_lateral furrow, LL_lateral lobes, LS - lobal septum, PP—posterior part of spermathecae.

Etymology. The species is dedicated to Helmut Steiner who collected a large amount of cave spiders and other cave-dwelling animals from SE Asia; name in genitive case.

Description. Female (holotype): Prosoma length 5.6, prosoma width 5.9, anterior width of prosoma 3.1, opisthosoma length 7.1, opisthosoma width 4.1. AME 0.28, ALE 0.42, PME 0.34, PLE 0.43, AME-AME 0.19, AME-ALE 0.05, PME-PME 0.25, PME-PLE 0.38, AME-PME 0.36, ALE-PLE 0.37, clypeus AME 0.40, clypeus ALE 0.35. Spination: Palp: 131, 101, 2121, 1014; legs: femur I-III 323, IV 331; patella I-IV 000; tibia I 1026, II 1(2)026, III-IV 2026; metatarsus I-II 0004, III 2016, IV 3036. Ventral metatarsus III with sparse double row of stiff bristles in proximal half, IV with dense double row of bristles along entire length and distal patch of bristles. 
Leg formula: 2413. Measurements of palp and legs: Palp 9.4 (2.9, 1.4, 2.1, -, 3.0), leg I 26.2 (7.1, 2.8, 7.5, 6.6, 2.2), leg II 28.8 (7.9, 3.1, 8.5, 7.1, 2.2), leg III 24.5 (7.1, 2.6, 6.9, 5.9, 2.0), leg IV 27.1 (7.6, 2.5, 7.5, 7.2, 2.3). Cheliceral furrow with 3 anterior and 4 posterior teeth, and with ca. 60 denticles in elongated patch close to anterior teeth. Margin of chelicerae close to fang base with one bristle. Palpal claw with 8 teeth. Sternum, ventral coxae and ventral femora covered sparsely with long setae, appendages and body otherwise with shorter setae.

Copulatory organ in diagnosis (Figs 1-3). Epigynal field wider than long, without anterior bands or slit sensilla. Lateral lobes fused, posteriorly with median incision. Epigynal pockets running from latero-posterior to medio-anterior, where copulatory openings are situated. Lateral furrows situated close to lateral ends of pockets, distinct, running to lateral margins of lateral lobes. Lobal septum moderately wide. Glandular appendages narrow, pointed, reaching posteriorly only barely posterior half of internal duct system. Posterior part of spermathecae bulging slightly laterally, fertilisation ducts arising posterio-laterally. Membranous expandable sac (as in Figs 19, 23) between fertilisation ducts reaching anterior end of internal duct system when expanded [dissected and stored in microvial]. Sclerotised spheres present along one epigynal pocket.

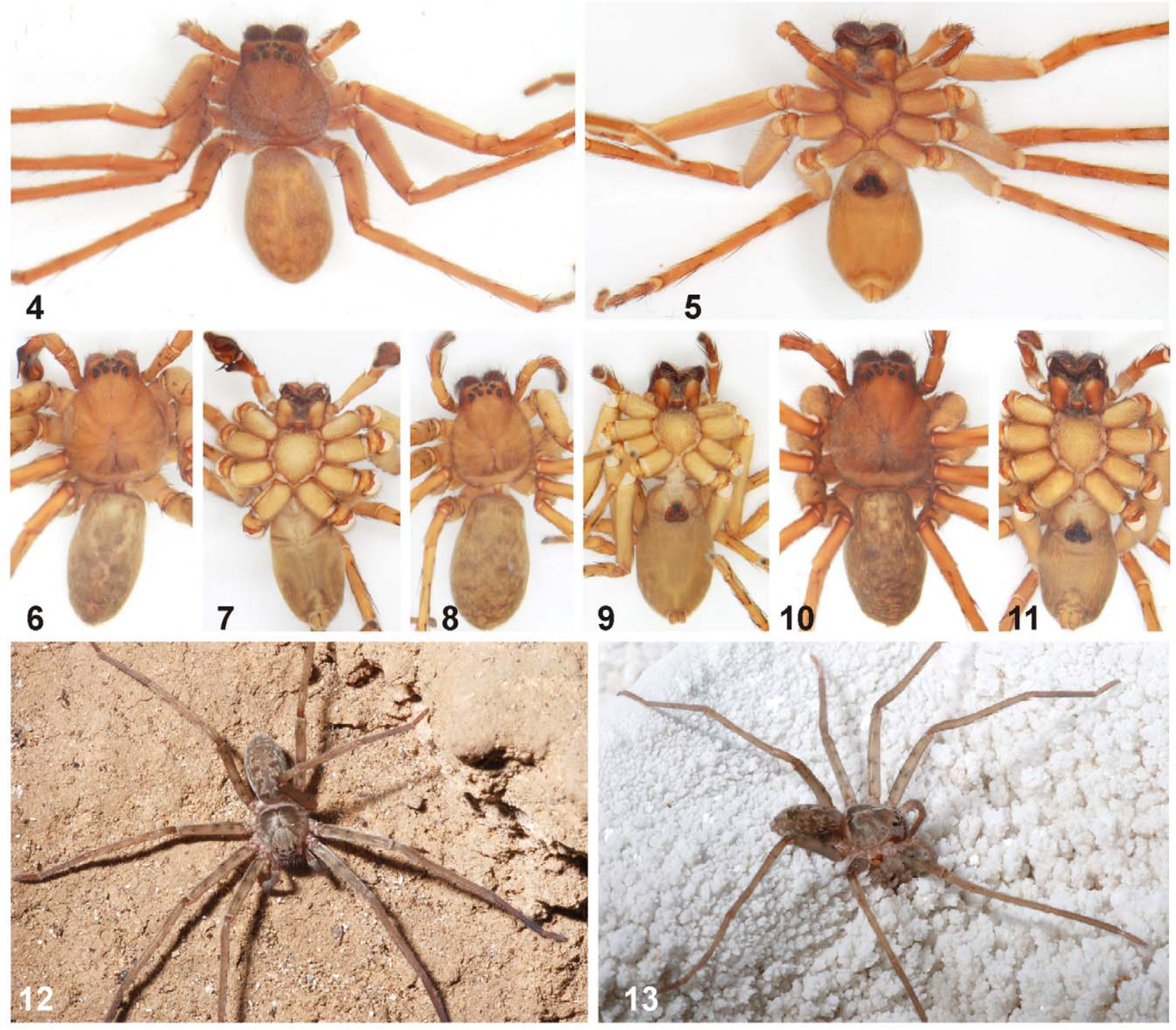

FIGURES 4-13. Sinopoda spp., habitus (4-11 preserved, 12-13 alive). 4-5 Sinopoda steineri spec. nov., holotype female from Ban Nam Eng, Luang Nam Tha; 6-13 Sinopoda tham spec. nov. from Oudomxai (6-7 holotype male from Chom Ong Cave System; 8-9 paratype female from Chom Ong cave system; 10-11 female from Tham Mokfek, 12-13 uncaught specimens from Chom Ong Cave systems). Photos 12-13 by H. Steiner.

Colouration in ethanol (Figs 4-5): Yellowish- to reddish-brown. Dorsal prosoma yellowish-brown with fovea and cuticular radial pattern reddish-brown. Sternum, ventral coxae and gnathocoxae yellowish-brown, labium red- 
dish-brown with distal part brighter. Chelicerae deep reddish-brown. Legs deep yellowish-brown. Dorsal opisthosoma with irregular pattern especially in posterior half, ventral opisthosoma without pattern, but with velvet-like appearance through dense cover of setae.

Male. Unknown.

Distribution. Only known from the type locality (Fig. 81).

\section{Sinopoda tham spec. nov.}

Figs 6-23, 81

Type material: Holotype: male, LAOS: Oudomxai Province: Xai District, Tham Chom Ong, N 2045'6.9", E $101^{\circ} 46^{\prime} 42.7^{\prime \prime}$ [800 m altitude], cave in limestone, by hand, 28 January 2010, W. Zillig leg., field number 066/10 (SMF, PJ 3372).

Paratypes: 4 females, with same data as for holotype (SMF, PJ 3373-3376).

Additional material examined ( 2 males, 12 females). 4 females with same data as for holotype, but: $\mathrm{N}$ 2043'6.3", E 101 ${ }^{\circ} 45^{\prime} 52.3^{\prime \prime}$ [750 m altitude], 19-21 January 2009, H. Steiner leg., field numbers 052/09, 049/09 (SMF, PJ 3296, SD 762; PJ 3378-3380); 2 subadult females, 4 juveniles, together with and with same data as for holotype (SMF). LAOS: Oudomxai Province: 1 male, 5 females, Namor District, Tham Na Thong, N20 52'20.6", E101 ${ }^{\circ} 46^{\prime} 57.8^{\prime \prime}$ [650 $\mathrm{m}$ altitude], cave in limestone, by hand, 26-31 January 2010, H. Steiner leg., field numbers 008/10, 010/10, 013/10, 040/10 (SMF, PJ 3299, SD 771; PJ 3300, SD 774; PJ 3377; PJ 3311, SD 787; PJ 3312; PJ 3310); 1 female, Namor District, Tham Mokfek, N2048'34.7", E101 47'14.5" [820 m altitude], cave in limestone, by hand, 27 January 2010, H. Steiner leg., field number 039/10, Northern Lao-European Cave Project (SMF, PJ 3307, SD 783); 1 male, La District, Tham Luang, N2049'12.2", E102'2'43.5" [870 m altitude], cave in limestone, by hand, 2 February 2010, H. Steiner leg., field number 005/10, Northern Lao-European Cave Project (SMF, PJ 3305, SD 781). LAOS: Luang Nam Tha Province: 2 females, Tham Ou Prang Ngiene, N20 32'33.8", E101 ${ }^{\circ}$ '11.8" [800 m altitude], cave in limestone, by hand, 8 February 2006, H. Steiner leg., field numbers 075/06, 040/06 (SMF, PJ 3384-3385).

Diagnosis. Medium-sized to large Heteropodinae, body length of males: 13.3-16.9, females: 13.8-22.3. Males (Figs 14-17) with characteristic shape and course of embolus, conductor and RTA (as e.g. in S. forcipata (Karsch, 1881)) may be recognised by: 1 . Embolus tip with thin transparent seam (may be absent/broken off) and distal part narrower, 2. dRTA long and slender with tip slightly widened, 3. vRTA compact and with ventral extension in retrolateral view (similar in S. tengchongensis Fu \& Zhu, 2008, but S. tham spec. nov. with dRTA closer to cymbium, embolus base covered by tegulum in ventral view, embolic apophysis tip slender, cymbium more elongated). Females (Figs 18-23) similar to those of S. triangula Liu et al., 2008 in having narrow, largely transversally oriented lateral lobes and epigynal pockets with a narrow lobal septum as well as internal duct system with long and narrow parallel part, but are distinguished from this and other Sinopoda spp. by 1. Posterior part of internal duct system bent at right angle, ca. of the same diameter/strength as longitudinal parallel part (much larger and ovalshaped in S. triangula), 2. Basal part of glandular appendages approximately parallel (distinctly diverging posteriorly in S. triangula). 3. Epigyne with anterior semicircular rim and lateral furrows longitudinally (without such rim and furrows in S. triangula).

Etymology. The species name is derived from the Lao word "tham" meaning "cave" and referring to the habitat at the type locality and the fact that the species was recorded exclusively in caves; term in apposition.

Description. Male (holotype): Prosoma length 8.1, prosoma width 7.1, anterior width of prosoma 3.7, opisthosoma length 8.8, opisthosoma width 5.1. AME 0.36, ALE 0.53, PME 0.39, PLE 0.52, AME-AME 0.22, AME-ALE 0.05, PME-PME 0.29, PME-PLE 0.47, AME-PME 0.41, ALE-PLE 0.38, clypeus AME 0.45, clypeus ALE 0.37. Spination: Palp: 131, 101, 2101; legs: femur I-III 323, IV 331; patella I-IV 101; tibia I-III 2326, IV 2226; metatarsus I-II 1014, III 2026, IV 3036. Ventral metatarsus III with sparse double row of stiff bristles in proximal half, IV with dense double row of bristles along entire length. Leg formula: 2143. Measurements of palp and legs: Palp 13.0 (4.5, 1.9, 2.4, -, 4.2), leg I 43.7 (11.1, 4.5, 12.1, 12.2, 3.8), leg II 48.3 (12.7, 4.6, 13.6, 13.5, 3.9), leg III $37.2(10.6,3.7,10.2,9.7,3.0)$, leg IV $40.8(11.2,3.9,11.1,11.2,3.4)$. Cheliceral furrow with 3 anterior and 4 posterior teeth, and with ca. 70 denticles in slightly elongated patch close to anterior teeth. Margin of chelicerae close to fang base with one bristle. Sternum, ventral coxae and femora, distal legs as well as frontal chelicerae with long setae, otherwise with shorter setae. 


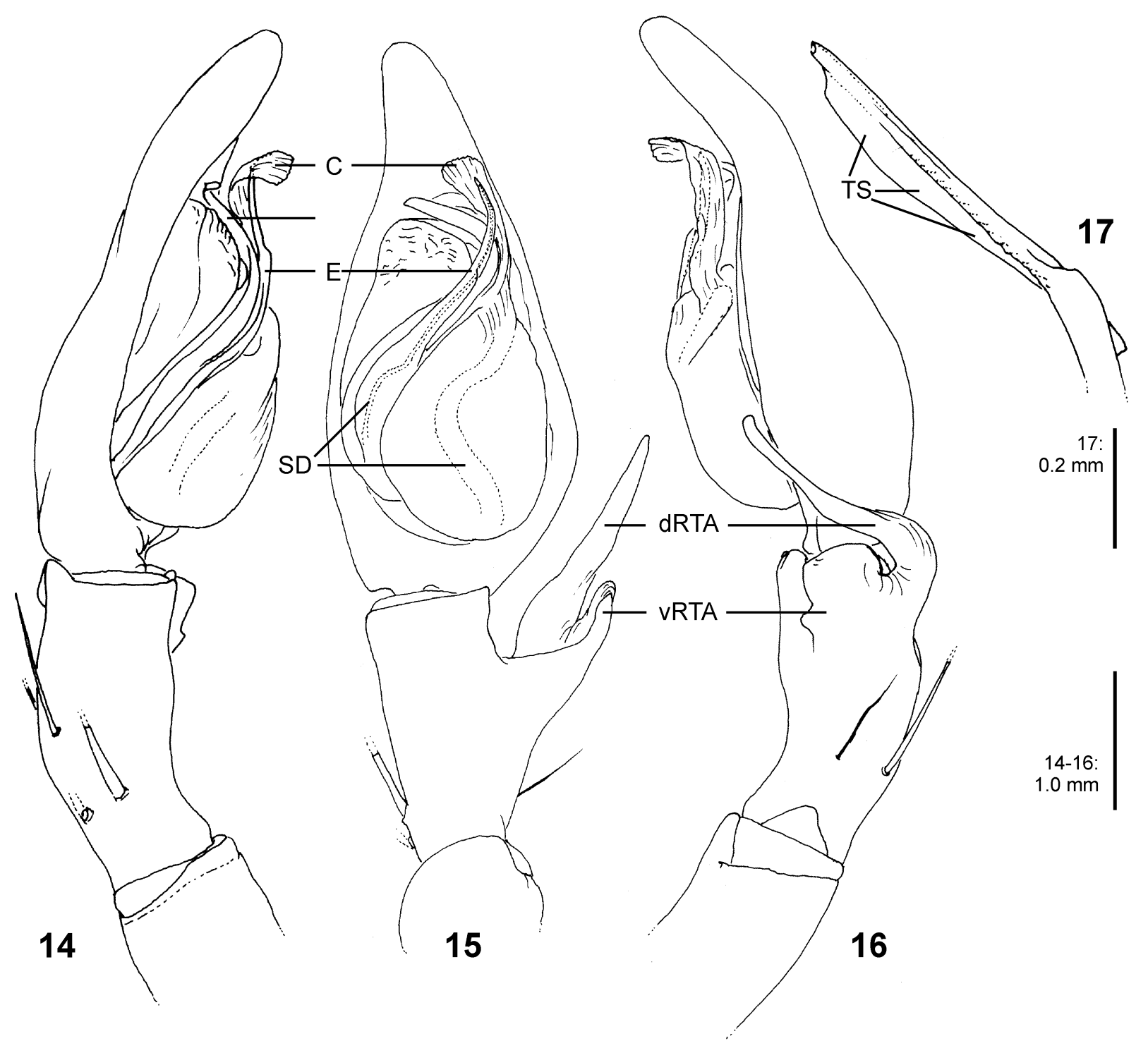

FIGURES 14-17. Sinopoda tham spec. nov., holotype male from Chom Ong cave system, Oudomxai, left male palp (14 prolateral, 15 ventral, 16 retrolateral, 17 tip of embolus, proximo-prolateral). C—conductor, E-embolus, dRTA—dorsal branch of RTA, SD—sperm duct, TS - transparent seam of distal embolus, vRTA - ventral branch of RTA.

Palp as in diagnosis (Figs 14-17). Cymbium much longer than tibia, RTA arising medially to proximally from tibia. Embolus arising in 7- to 8-o'clock-position from tegulum with tip only slightly bent, sperm duct with small bend in proximal half; tip of embolic apophysis bent at right angle. Conductor arising in 1-o'clock-position from tegulum, elongated laminar with distal part bent ventrally.

Colouration in ethanol (Figs 6-7): Yellowish- to slightly reddish-brown. Dorsal prosoma bright reddish-brown with cuticular radial pattern, most hairs rubbed off. Sternum, ventral coxae and femora, gnathocoxae, and labium pale yellowish-brown, gnathocoxae and labium proximally reddish-brown. Chelicerae reddish-brown. Legs reddish-brown with distal parts slightly darker, dorsal femora with faint pattern consisting of dark hairs. Dorsal opisthosoma with irregular pattern of small patches, darker (patches more dense) in posterior half. Ventral opisthosoma with book-lung margins darker, otherwise yellowish-brown without distinct pattern. Spinnerets yellowish-brown.

Female (paratype, PJ 3373): Prosoma length 7.0, prosoma width 6.1, anterior width of prosoma 3.5, opisthosoma length 10.3, opisthosoma width 6.2. AME 0.32, ALE 0.49, PME 0.35, PLE 0.48, AME-AME 0.20, AME-ALE 0.06, PME-PME 0.28, PME-PLE 0.41, AME-PME 0.40, ALE-PLE 0.41, clypeus AME 0.46, clypeus ALE 0.33. Spination: Palp: 131, 101, 2121, 1014; legs: femur I-III 323, IV 331; patella I-IV 001; tibia I-III 2026, IV 2126; metatarsus I-II 0004, III 2016, IV 3036. Ventral metatarsus III with sparse double row of stiff bristles in 
proximal half, IV with dense double row of bristles along entire length. Leg formula: 2413. Measurements of palp and legs: Palp 11.3 (3.3, 1.8, 2.6, -, 3.6), leg I 31.3 (8.7, 3.5, 9.0, 7.6, 2.5), leg II 34.4 (9.8, 3.9, 9.9, 8.3, 2.5), leg III 28.7 (8.3, 3.1, 8.1, 7.0, 2.2), leg IV 31.6 (9.1, 3.0, 8.6, 8.3, 2.6). Cheliceral furrow with 3 anterior and 4 posterior teeth, and with ca. 60 denticles in slightly elongated patch close to anterior teeth. Margin of chelicerae close to fang base with one bristle. Palpal claw with $7+1$ teeth. Sternum, ventral coxae and femora, distal legs as well as frontal chelicerae with long setae, otherwise with short setae.

Copulatory organ as in diagnosis (Figs 18-23). Epigynal field wider than long, with short anterior bands partly integrated in the field, with one slit sensillum on each side close to the epigynal field. Epigynal pockets half the length of posterior lateral lobes. Posterior epigynal margin with two slight humps. Some sclerotised spheres present along the median line in posterior half of epigyne. Anterior part of internal duct system swollen, i.e. broader than median part. Fertilisation ducts arising from small elevations medially on bent posterior part. Membranous sac between fertilisation ducts expandable, reaching anterior part of internal duct system if expanded (Fig. 19).

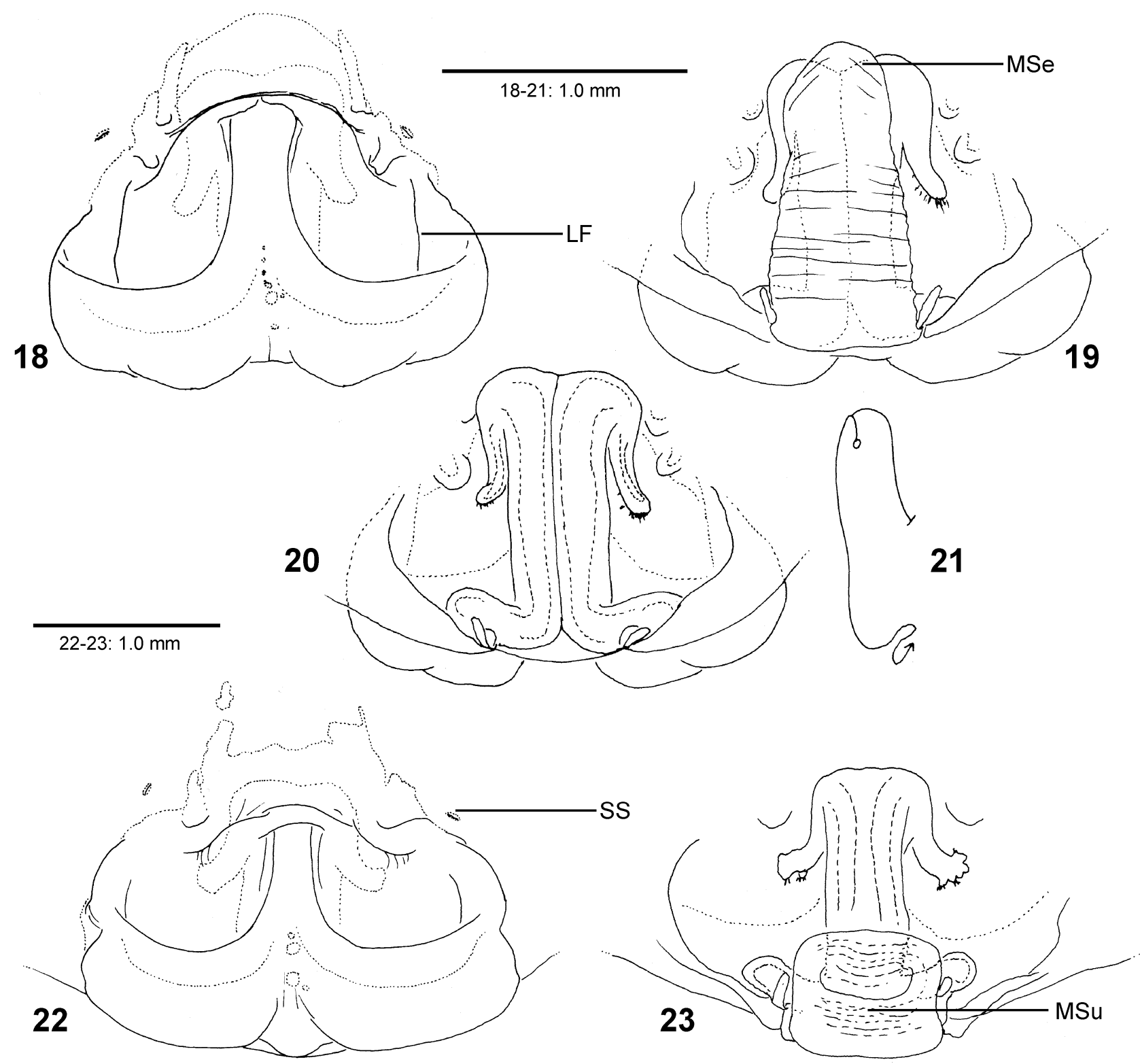

FIGURES 18-23. Sinopoda tham spec. nov., females from Oudomxai, copulatory organ (18, 22 epigyne, ventral; 19-20, 23 Vulva, dorsal; 21 schematic course of internal duct system, dorsal). See text for explanation. LF-lateral furrow, MSe-membranous sac expanded, MSu—membranous sac unexpanded, SS—slit sensillum. 
Colouration in ethanol (Figs 8-11): as in male, but: dorsal prosoma with cephalic part slightly darker and characteristic dark submarginal transversal band posteriorly. Chelicerae dark reddish-brown, gnathocoxae and labium reddish-brown with distal bright lip. Opisthosoma generally darker, spots on dorsal side more distinct. For colouration of live specimens see Figs 12-13.

Variation. Males PL 7.0, OL 7.6. Females PL 6.3-10.2, OL 7.5-12.8. In one male (PJ 3305) the characteristic dark transversal submarginal band on posterior dorsal prosoma was present. Moreover, the transparent seam of the embolus tip was absent/broken off (also in PJ 3399). All other characters of the male palp conform to those of the holotype. One male (PJ 3305) with 4 anterior teeth on its left chelicera. One female (PJ 3307) was darker than others with dark adpressed hairs almost on entire dorsal prosoma and with opisthosomal spots fused (Figs 10-11). Another female (PJ 3300; Figs 22-23) showed a considerably different epigyne and vulva: the two longitudinal lateral furrows anterior of the epigynal pockets were situated almost at the lateral end of the pockets, the lobal septum was shorter than in the paratype and there was a median bulge between the lateral lobes at the posterior margin of the epigyne. Glandular appendages were distinctly bent laterally at their widened tip. Since the syntopic male conforms to the holotype the differences in the female are considered intraspecific variation.

Distribution. Known from several caves in Oudomxai and Luang Nam Tha provinces (Fig. 81).

\section{Sinopoda sitkao spec. nov.}

Figs 24-26, 36-38, 81

Type material: Holotype: female, LAOS: Luang Prabang Province: Nam Ou, Muang Ngoi, Tham Doun Mai, N 2045'27.2", E 102 38'51.7" [ 370 m altitude], cave in limestone, by hand, 22 January 2012, H. Steiner leg., field number 064/12 (SMF, PJ 3388, SD 850).

Paratype: 1 female, with same data as for holotype, but field number 068/12 (SMF, PJ 3389).

Diagnosis. Medium-sized Heteropodinae, body length of females: 15.6. Females (Figs 24-26) similar to those of $S$. undata Liu et al., 2008 in having a relatively broad lobal septum and internal duct system with slim spermathecae, but are distinguished from this and other Sinopoda spp. by 1. Glandular appendages much shorter than in S. undata and not semicircular, 2. Posterior part wider than anterior part with glandular appendages, 3. Lateral lobes massive and not as narrow as in $S$. undata.

Etymology. The species name is derived and simplified from the Lao word "sîtkăao" meaning "pale" and referring to the fact that the species exhibits an overall pale appearance as typical for cave-dwellers; term in apposition.

Description. Female (holotype): Prosoma length 7.4, prosoma width 6.2, anterior width of prosoma 3.5, opisthosoma length 8.2, opisthosoma width 4.9. AME 0.31, ALE 0.48, PME 0.38, PLE 0.55, AME-AME 0.15, AME-ALE 0.04, PME-PME 0.29, PME-PLE 0.42, AME-PME 0.40, ALE-PLE 0.42, clypeus AME 0.61, clypeus ALE 0.50. Spination: Palp: 131, 101, 2121, 1114; legs: femur I-III 323, IV 331; patella I-III 001, IV 000; tibia I 2026, II-III 2126, IV 2226; metatarsus I-II 1014, III 2016, IV 3036. Ventral metatarsus III with sparse double row of stiff bristles in proximal half, IV with dense double row of bristles along entire length and distal patch of bristles. Leg formula: 2413. Measurements of palp and legs: Palp 13.1 (4.1, 1.9, 3.2, -, 3.9), leg I 41.5 (11.4, 4.2, 12.3, 11.3, 3.1), leg II 44.7 (12.8, 4.6, 13.9, 11.3, 3.1), leg III 38.8 (11.4, 3.7, 11.1, 9.8, 2.8), leg IV 42.2 (11.8, 3.5, 12.0, 11.8, 3.1). Cheliceral furrow with 3 anterior and 4 posterior teeth, and with ca. 25-30 denticles in restricted patch close to anterior teeth. Margin of chelicerae close to fang base with one bristle. Palpal claw with $9+1(10+1)$ teeth. Sternum, ventral coxae and ventral femora covered sparsely with long setae, frontal chelicerae with dense cover of long setae, otherwise with shorter setae.

Copulatory organ in diagnosis (Figs 24-26). Epigynal field as wide as long, with two long anterior bands and one slit sensillum on the left side close to the field. Lateral lobes fused, posteriorly with only slight median indentation. Epigynal pockets running from lateral to medio-anterior, where copulatory openings are situated. Lateral furrows distinct, longitudinal. Glandular appendages extending not in posterior half of internal duct system. Spermathecae diverging as a "V" posteriorly, fertilisation ducts arising posteriorly, long and laminar. Few sclerotised spheres present at median junction of lateral lobes. 


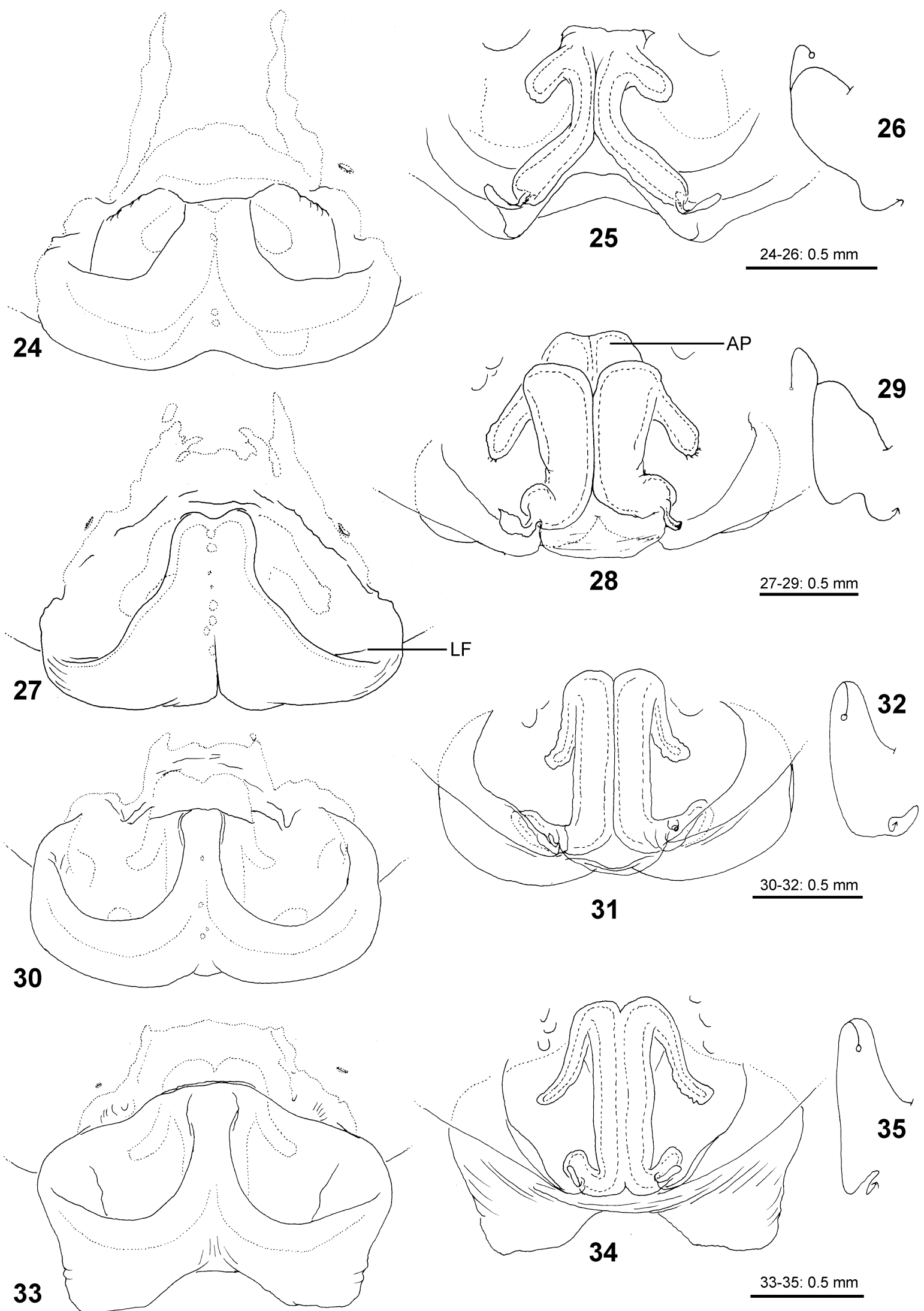

FIGURES 24-35. Sinopoda spp. females, copulatory organ. 24-26 Sinopoda sitkao spec. nov. holotype from Tham Doun Mai, Luang Prabang; 27-29 Sinopoda taa spec. nov. holotype from Tham Ngiene, Luang Prabang; 30-32 Sinopoda suang spec. nov. holotype from Tham Ho Neung, Huaphan; 33-35 Sinopoda peet spec. nov. holotype from Tham Ma Liong, Huaphan (24, 27, 30, 33 epigyne, ventral; 25, 28, 31, 34 vulva, dorsal; 26, 29, 32, 35 schematic course of internal duct system, dorsal). AP-anterior part of internal duct system, LF-lateral furrow. 
Colouration in ethanol (Figs 36-38): Yellowish-brown. Dorsal prosoma yellowish-brown with cephalic part slightly reddish-brown, covered by dark-grey hairs, except for characteristic transversal band posteriorly, fovea distinct, radial striae indistinct. Sternum and ventral coxae pale yellowish-brown, gnathocoxae and labium slightly reddish-brown. Chelicerae deep reddish-brown. Legs yellowish-brown. Opisthosoma uniformly greyish-brown covered by short dark-grey setae. Spinnerets reddish-brown.

Male. Unknown.

Variation. Paratype female with PL 7.2, OL 8.3.

Distribution. Only known from the type locality (Fig. 81).

\section{Sinopoda taa spec. nov.}

Figs 27-29, 39-40, 81

Type material: Holotype: female, LAOS: Luang Prabang Province: Tham Nguen, N 1952'37.4", E 102 ${ }^{\circ} 10^{\prime} 6.7^{\prime \prime}$ [500 m altitude], cave in limestone, by hand, 26 December 2010, H. Steiner leg., field number 053/04 LP 26-1 (SMF, PJ 3381).

Diagnosis. Medium-sized Heteropodinae, body length of female: 18.3. Females (Figs 27-29) similar to those of S. fornicata Liu et al., 2008 in having lateral lobes appearing as large triangle and internal duct system with anterior part (copulatory ducts) appearing as separated swelling, but are distinguished from this and other Sinopoda spp. by 1. Margins of epigynal pockets concave and slightly undulating, 2. Anterior part of internal duct system (without glandular appendages) wider than posterior part (without bent spermathecae).

Etymology. The species name is derived from the Lao word "taa" meaning "eye" and referring to the fact that all eight eyes are developed; term in apposition.

Description. Female (holotype): Prosoma length 8.3, prosoma width 7.2, anterior width of prosoma 4.1, opisthosoma length 10.0, opisthosoma width 5.8. AME 0.31, ALE 0.58, PME 0.38, PLE 0.62, AME-AME 0.18, AME-ALE 0.06, PME-PME 0.24, PME-PLE 0.50, AME-PME 0.53, ALE-PLE 0.42, clypeus AME 0.58, clypeus ALE 0.49. Spination: Palp: 131, 101, 2121, 1014; legs: femur I 323, II-III 333, IV 331; patella I-III 001, IV 000; tibia I-II 2026, III-IV 2126; metatarsus I-II 1014, III 2014, IV 3036. Ventral metatarsus III with sparse double row of stiff bristles in proximal half, IV with dense double row of bristles along entire length and distal patch of bristles. Leg formula: 2413. Measurements of palp and legs: Palp 14.3 (4.5, 2.0, 3.2, -, 4.6), leg I 44.7 (12.2, 4.6, 13.4, 11.4, 3.1), leg II 48.2 (13.5, 5.0, 14.5, 12.1, 3.1), leg III 41.9 (12.2., 4.3, 12.3, 10.1, 3.0), leg IV 45.1 (12.6, 4.1, 12.9, $12.3,3.2)$. Cheliceral furrow with 3 anterior and 4 posterior teeth, and with ca. 30-35 denticles in slightly elongated patch close to anterior teeth. Margin of chelicerae close to fang base with one bristle. Palpal claw with 9+1 (10+1) teeth. Sternum, ventral coxae and ventral femora covered sparsely with long setae, otherwise with shorter setae.

Copulatory organ in diagnosis (Figs 27-29). Epigynal field wider than long, with two short anterior bands (partly fused with field) and one slit sensillum on each side close to the field. Lateral lobes partly fused, posteriorly with almost transversally straight margin and slight median incision. Epigynal pockets running from posteriorlateral to medio-anterior, where copulatory openings are situated. Lateral furrows situated close to lateral ends of pockets, transversally oriented, indistinct. Lobal septum moderately wide. Glandular appendages extending posteriorly in posterior half of internal duct system. Spermathecae bulging laterally, fertilisation ducts arising posterio-laterally, long and leaf-shaped laminar. Sclerotised spheres present at entire median junction of lateral lobes.

Colouration in ethanol (Figs 39-40): Yellowish-brown without pattern. Dorsal prosoma yellowish-brown with fovea and cuticular radial pattern reddish-brown. Sternum and ventral coxae pale yellowish-brown, gnathocoxae deep yellowish-brown, labium reddish-brown. Chelicerae deep reddish-brown. Legs yellowish-brown. Opisthosoma including spinnerets greyish- to yellowish-brown.

Male. Unknown.

Distribution. Only known from the type locality (Fig. 81). 

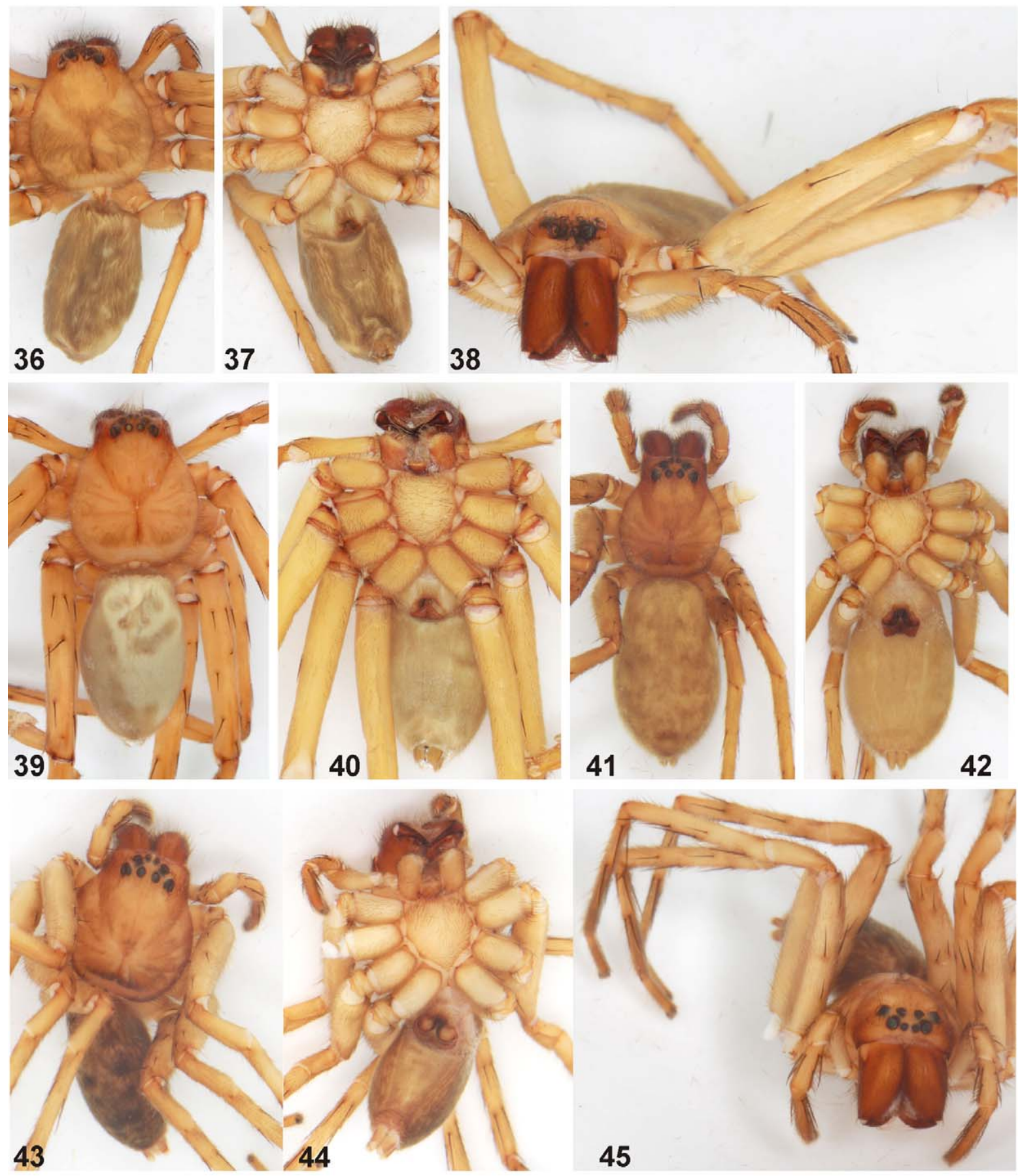

FIGURES 36-45. Sinopoda spp. females, habitus. 36-38 Sinopoda sitkao spec. nov. holotype from Tham Doun Mai, Luang Prabang; 39-40 Sinopoda taa spec. nov. holotype from Tham Ngiene, Luang Prabang; 41-42 Sinopoda peet spec. nov. holotype from Tham Ma Liong, Huaphan; 43-46 Sinopoda suang spec. nov. holotype from Tham Ho Neung, Huaphan.

\section{Sinopoda suang spec. nov.}

Figs 30-32, 43-45, 81

Type material: Holotype: female, LAOS: Huaphan Province: Vieng Thong, Tham Ho Neung, N 20²7'5.5", E 10320'59.0" [750 m altitude], cave in limestone, by hand, 19 January 2010, H. Steiner leg., field number 015/10, Northern Lao-European Cave Project (SMF, PJ 3387). 
Diagnosis. Medium-sized Heteropodinae, body length of female: 11.8. Females (Figs 30-32) similar to those of $S$. tham spec. nov. in having a similar internal duct system with parallel part long, glandular appendages long, narrow and only slightly diverging posteriorly, posterior part wider than anterior part with glandular appendages, but are distinguished from this and other Sinopoda spp. by 1. Epigynal pockets almost semicircular, running parallel to posterior margin of lateral lobes, 2. Lateral furrows absent.

Etymology. The species name is derived from the Lao word "suang" meaning "hidden" and referring to the hidden lifestyle in caves of Sinopoda species; term in apposition. Pronunciation note: the vowel "ua" of the Lao alphabet is pronounced as the "ür" in the German "Tür".

Description. Female (holotype): Prosoma length 5.0, prosoma width 4.5, anterior width of prosoma 2.7, opisthosoma length 5.3, opisthosoma width 2.8. AME 0.22, ALE 0.40, PME 0.29, PLE 0.40, AME-AME 0.23, AME-ALE 0.07, PME-PME 0.29, PME-PLE 0.41, AME-PME 0.39, ALE-PLE 0.39, clypeus AME 0.42, clypeus ALE 0.33. Spination: Palp: 131, 101, 2121, 1014; legs: femur I-III 323, IV 331; patella I-IV 000; tibia I-III 2026, IV 2126; metatarsus I-II 0004, III 2016, IV 3036. Ventral metatarsus I with few stiff bristles proximally, II with some setae (most of them in one row) restricted to proximal half, III with sparse double row of bristles along entire length, IV with the same as in III but with additional dense distal patch of bristles. Leg formula: 2413. Measurements of palp and legs: Palp 7.4 (2.2, 1.2, 1.7, -, 2.3), leg I 19.0 (5.2, 2.2, 5.3, 4.6, 1.7), leg II 21.9 (6.2, 2.5, 6.2, 5.2, 1.8), leg III 17.9 (5.2, 2.2, 4.7, 4.3, 1.5), leg IV 19.5 (5.7, 2.0, 5.4, 5.5, 1.9). Cheliceral furrow with 3 anterior and 4 posterior teeth, and with ca. 55 denticles in patch close to anterior teeth. Margin of chelicerae close to fang base with one bristle. Palpal claw with 7 teeth. Sternum, ventral coxae and ventral femora covered sparsely with long setae, chelicerae with dense cover of long setae, otherwise with shorter setae.

Copulatory organ as in diagnosis (Figs 30-32). Epigynal field wider than long, without anterior bands and slit sensilla. Lateral lobes fused and with indistinct broad median incision. Epigynal pockets running from anteriolateral to medio-anterior, where copulatory openings are situated. Lobal septum moderately wide to narrow. Glandular appendages extending in anterior half of internal duct system. Posterior spermathecae bulging laterally and slightly anteriorly, fertilisation ducts arising anterio-medially from the posterior part.

Colouration in ethanol (Figs 43-45): Yellowish-brown with dark pattern. Dorsal prosoma yellowish-brown with fovea and cuticular radial pattern reddish-brown, posterior part with characteristic transversal dark band at posterior end of fovea, lateral margins dark especially in posterior half. Sternum, gnathocoxae and ventral coxae pale yellowish-brown, labium reddish- to yellowish-brown. Chelicerae reddish-brown with slightly marked longitudinal bands. Legs uniformly yellowish-brown. Dorsal opisthosoma dark-brown with 4-6 pairs of dark patches, lateral opisthosoma mottled, ventral opisthosoma without pattern. Spinnerets reddish-brown.

Male. Unknown.

Distribution. Only known from the type locality (Fig. 81).

\section{Sinopoda peet spec. nov.}

Figs 33-35, 41-42, 81

Type material: Holotype: female, LAOS: Huaphan Province: Tham Ma Liong, N 20 24'22.60", E $104^{\circ} 14^{\prime} 58.90^{\prime \prime}$ [820 m altitude], cave in limestone, by hand, 17 January 2008, H. Steiner leg., field number 092/08, Northern Lao-European Cave Project (SMF, PJ 3386).

Diagnosis. Medium-sized Heteropodinae, body length of female: 11.8. Females (Figs 33-35) similar to those of S. steineri spec. nov. in having a similar internal duct system with parallel part long, glandular appendages long and narrow, posterior part narrower than anterior part with glandular appendages, and to those of $S$. tham spec. nov. in having a similar course of epigynal pockets and in lateral furrows sub-parallel, but are distinguished from these and other Sinopoda spp. by 1. Posterior part of spermathecae bent strongly, running almost a U-turn (bent at right angle in S. steineri spec. nov. and S. tham spec. nov.), 2. Lateral lobes with strongly bilobal posterior margin (not so in other Laotian Sinopoda species), 3. Lateral margins of epigynal pockets pointing anterio-laterally (pointing laterally in $S$. tham spec. nov.).

Etymology. The species name is derived from the Lao word "peet [bpect]" meaning "eight" and referring to the fact that all eight eyes are developed; term in apposition. Pronunciation note: the long vowel " $\varepsilon \varepsilon$ " of the Lao alphabet is pronounced as the "a" in the English "sad" or the "ä" in the German "gähnen". 
Description. Female (holotype): Prosoma length 4.7, prosoma width 4.2, anterior width of prosoma 2.7, opisthosoma length 7.1, opisthosoma width 4.2. AME 0.23, ALE 0.42, PME 0.29, PLE 0.42, AME-AME 0.15, AME-ALE 0.07, PME-PME 0.23, PME-PLE 0.39, AME-PME 0.37, ALE-PLE 0.35, clypeus AME 0.32, clypeus ALE 0.24. Spination: Palp: 131, 101, 2121, 1014; legs: femur I-III 323, IV 331; patella I-IV 000; tibia I-IV 2026; metatarsus I-II 0004, III 2016, IV 3036. Ventral metatarsus I with short double row of stiff bristles proximally, II with a slightly longer row also restricted to proximal half, III with dense double row of bristles along entire length and IV with the same as in III but with additional dense distal patch of bristles. Leg formula: 2413. Measurements of palp and legs: Palp 7.3 (2.1, 1.2, 1.6, -, 2.3), leg I 20.7 (5.6, 2.3, 6.1, 5.0, 1.7), leg II 23.1 (6.5, 2.6, 6.8, 5.4, 1.8), leg III $19.5(5.4,2.7,5.5,4.7,1.7)$, leg IV $21.3(5.7,2.2,5.9,5.6,1.9)$. Cheliceral furrow with 3 anterior and 4 posterior teeth, and with ca. 45 denticles in elongated patch close to anterior teeth. Margin of chelicerae close to fang base with one bristle. Palpal claw with 8 teeth. Sternum, ventral coxae and ventral femora covered sparsely with long setae, chelicerae with dense cover of long setae, otherwise with shorter setae.

Copulatory organ as in diagnosis (Figs 33-35). Epigynal field wider than long, with anterior bands fused with field and one slit sensillum on each side slightly separated from the field. Lateral lobes fused and with broad median incision. Epigynal pockets running from (anterio)-lateral to medio-anterior, where copulatory openings are situated. Lateral furrows situated apart from lateral ends of pockets, almost longitudinally oriented, distinct. Lobal septum moderately wide. Glandular appendages extending barely to posterior half of internal duct system. Posterior spermathecae bulging laterally, fertilisation ducts arising medially from the posterior part.

Colouration in ethanol (Figs 43-45): Yellowish-brown. Dorsal prosoma yellowish-brown with fovea and cuticular radial pattern reddish-brown, posterior part with characteristic transversal bright and dark band. Sternum and ventral coxae pale yellowish-brown, gnathocoxae and labium reddish- to yellowish-brown. Chelicerae deep reddish-brown. Legs uniformly yellowish-brown, distally slightly darker. Dorsal opisthosoma with indistinct irregular pattern, ventral opisthosoma almost without pattern.

Male. Unknown.

Distribution. Only known from the type locality (Fig. 81).

\section{Sinopoda guap spec. nov.}

Figs 46-54, 81

Type material: Holotype: female, LAOS: Khammuan Province: Tham Nam Non, $25 \mathrm{~km}$ SE Na Hin, N18 01'42.3", E10441'24.0", [260 m altitude]river cave in limestone, by hand, 16 February 2004, H. Steiner leg., field number 118/04 (SMF, PJ 3370).

Additional material examined. 1 juvenile, with same data as for holotype except: 15 February 1999, Lordon \& Vacquie leg., field number LAO-070 NamNon1 (SMF, PJ 3371).

Diagnosis. Medium sized Heteropodinae, body length of female: 13.6. Females (Figs 51-54) may be distinguished from other Sinopoda spp. by having six small lenses without pigments with AME lacking (Fig. 50). Epigynal pockets forming unique circular margin around copulatory atrium. Lateral lobes fused, strongly developed, bulging ventrally and with two distinct posterior lobes. Internal duct system diverging from copulatory openings, only posterior part subparallel.

Etymology. The species name is derived from the Lao word "guap" meaning "almost, nearly" and referring to the almost completely reduced eyes; term in apposition. Pronunciation note: the vowel "ua" of the Lao alphabet is pronounced as "ür" in the German "Tür".

Description. Female (holotype): Prosoma length 5.8, prosoma width 5.0, anterior width of prosoma 2.8, opisthosoma length 7.8, opisthosoma width 3.4. AME including lenses and pigments absent, remnants of lenses of ALE, PME and PLE present (Fig. 50): ALE 0.15, PME 0.03, PLE 0.05. Spination: Palp: 131, 101, 2121, 1114; legs: femur I-III 323, IV 321(211); patella I-IV 000; tibia I 20(2)26, II-III 2226, IV 21(0)26; metatarsus I-II 1014, III 2014, IV 3026. Ventral leg metatarsus I without distal bristles, II with a single bristle, III with a bunch of short bristles distally, IV with distal bunch of bristles and a double row of bristles along entire length. Leg formula: 2143. Measurements of palp and legs: Palp 10.9 (3.3, 1.4, 2.6, -, 3.6), leg I 32.4 (9.1, 3.0, 9.8, 8.3, 2.2), leg II 35.3 (9.6, 3.5, 11.0, 9.0, 2.2), leg III 31.4 (8.8, 3.2, 9.2, 8.1, 2.1), leg IV 32.2 (8.9, 2.8, 9.3, 8.9, 2.3). Cheliceral furrow with 3 anterior and 4 posterior teeth, and with restricted patch of denticles close to anterior teeth. Margin of chelicerae 
close to fang base with one bristle. Palpal claw with 9 teeth. Sternum (Fig. 49), ventral coxae and femora, distal legs as well as frontal chelicerae with long setae, otherwise with short setae.

Copulatory organ as in diagnosis (51-54). Epigynal field wider than long, with only short and narrow anterior bands, no slit sensilla could be recognised. Glandular appendages short, only seen in lateral view, duct system simple, almost linear with one widened chamber in the middle part. Many sclerotised spheres present dorsally along posterior margin of internal duct system.

Colouration in ethanol (Figs 46-50): Yellowish-brown without pattern. Dorsal prosoma with gnathocoxae, labium and cephalic part slightly darker than thoracic part, fovea marked reddish-brown. Chelicerae strongly reddish-brown.

Male. Unknown.

Distribution. Only known from the type locality (Fig. 81).
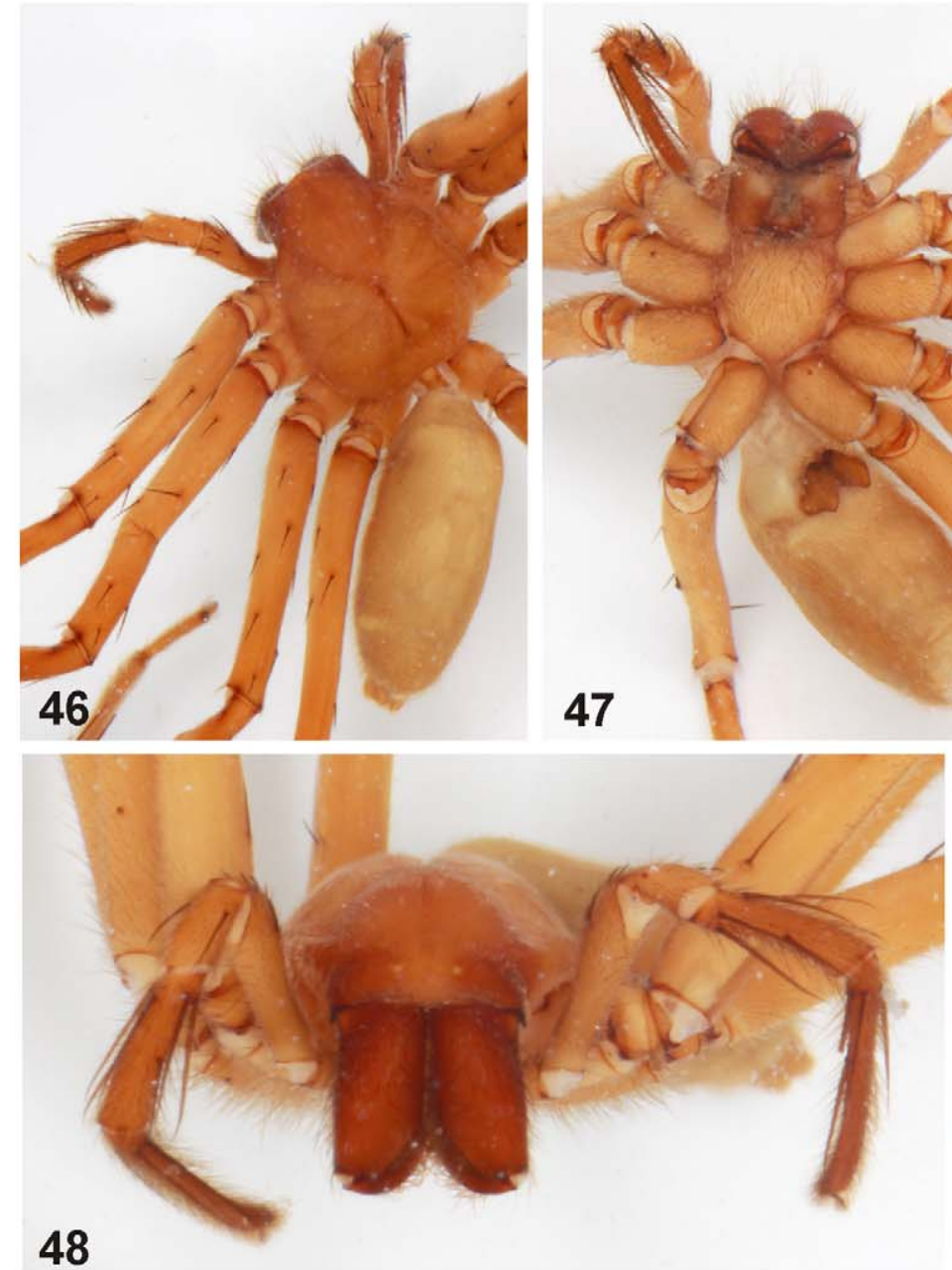
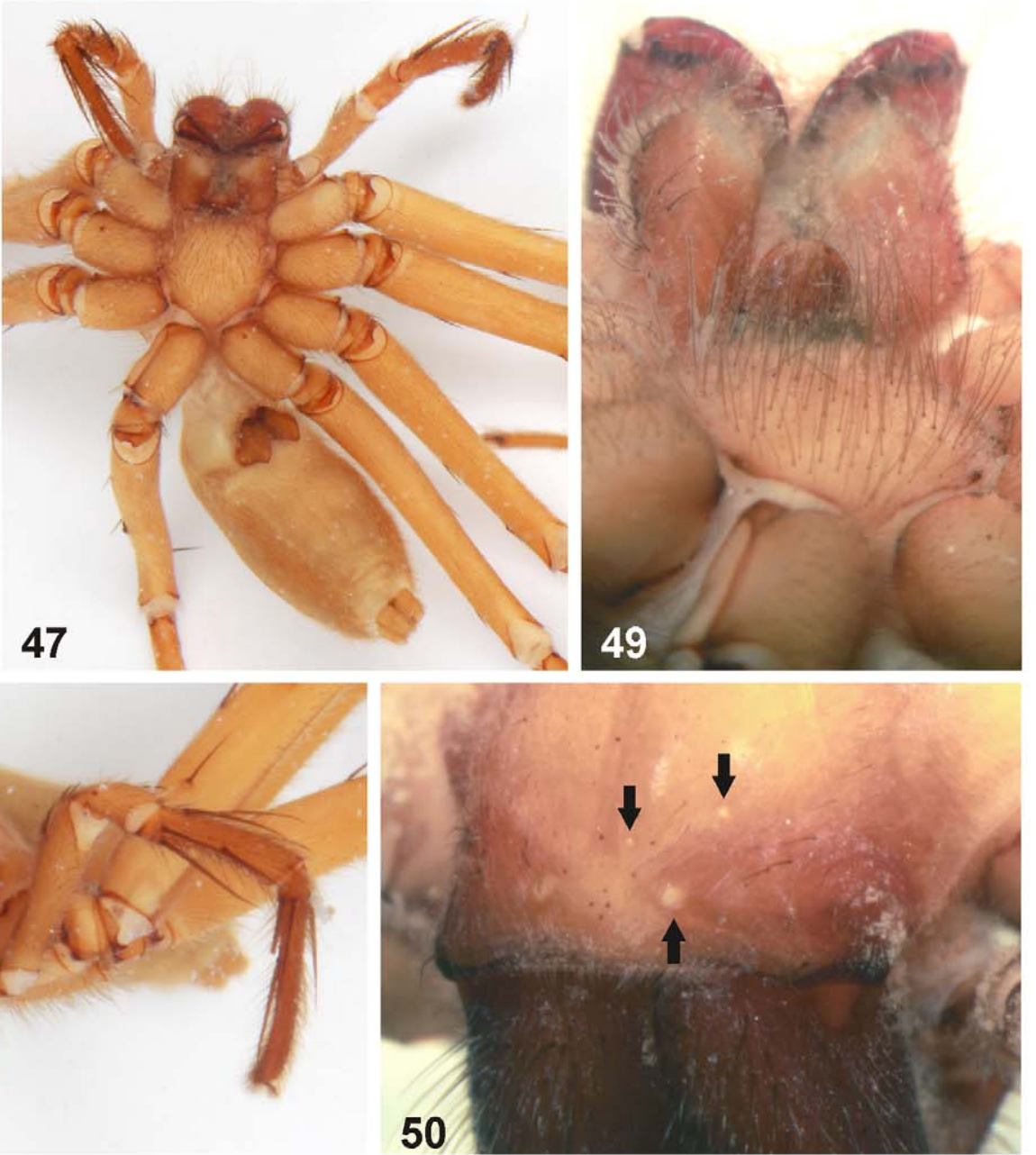

FIGURES 46-50. Sinopoda guap spec. nov. holotype from Tham Nam Non, Khammuan. $46-48$ Habitus (46 dorsal, 47 ventral, 48 frontal); 49 Prosoma, ventral, showing long setae; 50 Prosoma, frontal. Arrows pointing to lenses of ALE, PME and PLE.

\section{Sinopoda soong sp. nov}

Figs 55-60, 66-75, 81

Type material: Holotype: female, LAOS: Khammuan Province: $15 \mathrm{~km}$ N Thakek, Tham Pha Yot ("cave of the dropping cliff"), N17³2'57.24", E10448'45.23" [200 m altitude], cave in limestone, aphotic zone, c. $25^{\circ} \mathrm{C}$, at day, by hand, 29 April 2012, P. Jäger leg. (SMF, PJ 3366). 


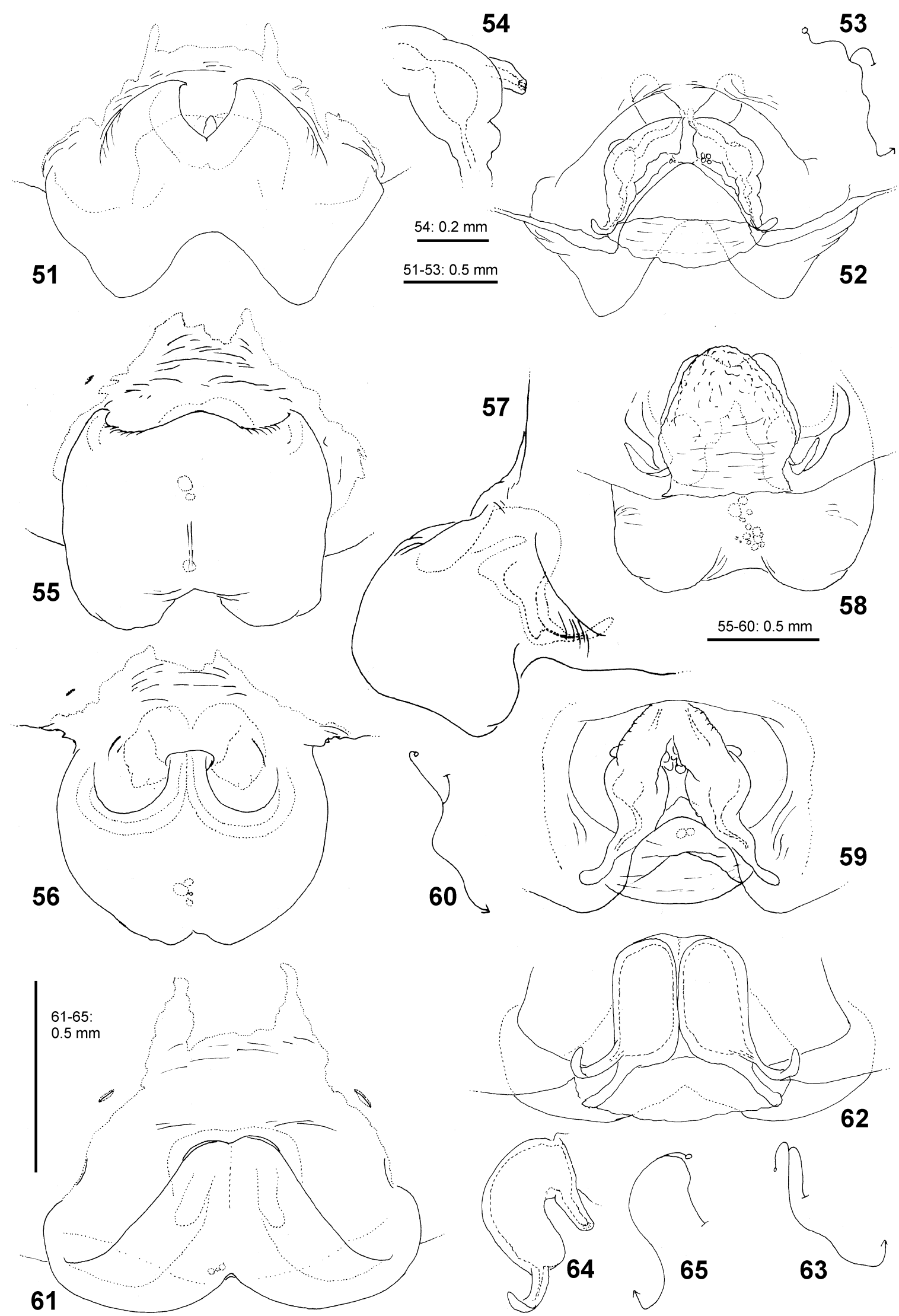

FIGURES 51-65. Sinopoda spp. holotype females, copulatory organ. 51-54 Sinopoda guap spec. nov. from Tham Nam Non, Khammuan;. 55-60 Sinopoda soong spec. nov. from Tham Pha Yot, Khammuan;. 60-65 Sinopoda scurion spec. nov. from foot cave close to Thakek, Khammuan. (51, 55, 61 epigyne, ventral; 52, 58, 62 vulva, dorsal [58 with membranous sac expanded]; 53, 60, 63, 65 schematic course of internal duct system; 54, 64 right half of internal duct system, lateral; 56 epigyne, frontal; 57 epigyne, lateral; 59 vulva, frontal). 

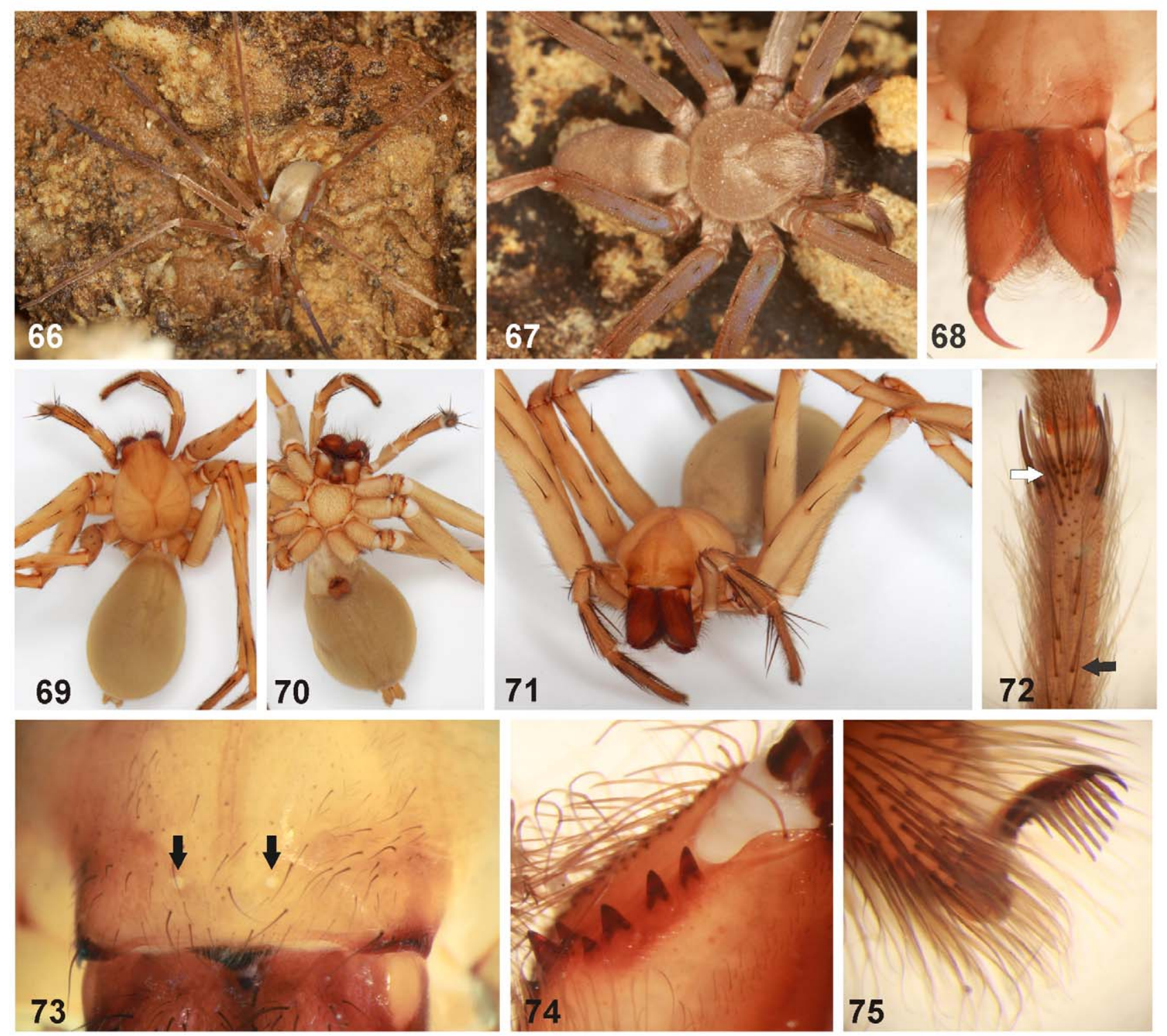

FIGURES 66-75. Sinopoda soong spec. nov. holotype female from Tham Pha Yot, Khammuan. 66-71 Habitus (66-67, 69 dorsal, 68, 71 frontal, 70 ventral); 72 distal metatarsus IV, ventral, showing distal patch of bristles (white arrow) and double row of bristles (black arrow); 73 Prosoma, frontal, showing eye lenses of ALE (arrows); 74 Left chelicera, ventral; 75 Palpal claw.

Additional material examined. LAOS: Khammuan Province: 1 subadult female, 18 km NNW Thakek, Ban Phalem, Tham Koun Don, N 17³3'49.2", E 10452'18.7"E [206 m altitude], in cave, by hand, 24 February 2006, 197/06, H. Steiner leg., field number 197/06, French Khammuan expedition (SMF).

Diagnosis. Medium sized Heteropodinae, body length of female: 15.1. Females may be distinguished from other Sinopoda species by having only two eye lenses (ALE: Fig. 73). Vulva similar to that of S. guap spec. nov., but $S$. soong spec. nov. is distinguished by the massive roughly quadrangular shape of its epigyne in ventral view (Fig. 55). Epigynal pockets forming two semicircles in anterior view (Fig. 56).

Etymology. The species name is derived from the Lao word "soong" meaning "two" and referring to the number of eye lenses; term in apposition.

Description. Female (holotype): Prosoma length 5.9, prosoma width 4.8, anterior width of prosoma 2.6, opisthosoma length 9.2, opisthosoma width 5.9. Eyes: two lenses without pigments present. ALE 0.09, ALE-ALE 0.61. Spination: Palp: 131, 101, 2121, 1114; legs: femur I-III 323, IV 321; patella I-III 001, IV 000; tibia I 2126, II-IV 2226; metatarsus I-II 1014, III 2014, IV 3036. Ventral leg metatarsi I-II with c. 10 short bristles distally, metatarsus III-IV with c. 20 bristles (Fig. 72) and additionally with double row of bristles, the latter in III in proxi- 
mal half, in IV along entire length (Fig. 72). Leg formula: 2413. Measurements of palp and legs: Palp 11.0 (3.4, 1.5, 2.5, -, 3.6), leg I $34.4(9.3,3.5,10.4,9.1,2.1)$, leg II $36.3(10.3,3.7,11.0,9.2,2.1)$, leg III $32.2(9.1,3.2,9.5$, 8.4, 2.0), leg IV $34.6(9.6,3.2,9.8,9.8,2.1)$. Cheliceral furrow with 3 anterior and 4 posterior teeth (Fig. 74), and with restricted patch of c. 40 denticles close to anterior teeth. Margin of chelicerae close to fang base with one bristle (Fig. 74). Palpal claw with 9-11 teeth (Fig. 75). Sternum, ventral coxae and femora, distal legs as well as frontal chelicerae with long setae, otherwise with short setae.

Copulatory organ as in diagnosis (Figs 55-60). Epigynal field as wide as long, with two very short anterior bands and one slit sensillum on the left side close to the field. Lateral lobes fused, posteriorly bilobal; bulging extremely ventrally. Glandular appendages short, only parts visible in anterior view. Spermathecae bulging to the dorsal side, fertilisation ducts arising posteriorly, long and narrowly laminar. Sclerotised spheres present dorsally and ventrally at median (fusion) line of lateral lobes. Expanded membranous sac reaching anterior end of duct system, shorter than that of $S$. tham spec. nov., almost as long as wide.

Colouration in ethanol (Figs 68-71, 73): Uniformly yellowish-brown without pattern. Dorsal prosoma with cephalic part slightly darker than thoracic part, fovea and faint radial pattern slightly darker. Chelicerae reddish brown, labium and parts of gnathocoxae reddish-brown. Opisthosoma uniformly pale grey-brown. For colouration of live specimens see Figs 66-67.

Male. Unknown.

Distribution. Only known from the type locality (Fig. 81).

Biology. Specimens were collected in the aphotic zone of the limestone cave. They were recorded together with specimens of Typopeltis magnificus Haupt, 2004 (Arachnida: Uropygi: Thelyphonidae). In the entrance area (50-150 m apart) Heteropoda maxima was recorded.

\section{Sinopoda scurion spec. nov.}

Figs 61-65, 76-81

Type material: Holotype: female, LAOS: Khammuan Province: $9.5 \mathrm{~km}$ NE Thakek, N17²6.936', E104 ${ }^{\circ} 52.499^{\prime}, 159 \mathrm{~m}$ altitude, foot cave in limestone, aphotic zone, c. $25^{\circ} \mathrm{C}$, at day, by hand, 6 November 2009, P. Jäger \& S. Bayer leg. (SMF, PJ 3366).

Paratypes: 2 females with same data as for holotype (SMF, PJ 3367-3368); 1 female with same data as for holotype, except: 28 February 2003, P. Jäger leg. (SMF, PJ 3369).

Additional material examined. 1 female (without opisthosoma), 1 subadult male, 7 subadult females, 15 juveniles, all same data as holotype, but: 1 female (without opisthosoma), 2 subadult females, 3 juveniles, 1 March 2007, P. Jäger \& F. Steinmetz leg.; 3 subadult females, 1 juvenile (SMF, together with PJ 3367-3368); 1 subadult female, 1 juvenile, 29 October 2004, P. Jäger \& V. Vedel leg. (SD 109); 1 subadult male, 1 juvenile, 8 December 2005, V. Vedel leg.; 1 subadult female, 8 juveniles, 28-31 October 2004, P. Jäger \& V. Vedel leg.; 1 juvenile (in moult), 25 April 2012, P. Jäger leg.

Diagnosis. Medium sized Heteropodinae, body length of females: 10.9-13.6. Females (Figs 61-65) may be distinguished from other Sinopoda species by having no eyes or remnants of lenses (Figs 76-79). Glandular appendages situated ventrally, only visible in lateral view. Epigynal pockets forming a triangle. Spermathecae simple, each approximately two times longer than wide, parallel and touching each other along median line, without lateral bulging, kidney-shaped in lateral view.

Etymology. In honour of the Swiss company SCURION® for supporting the systematic research, description of biodiversity and nature conservation in Laos, especially in caves due to their perfectly developed head-lights; noun in genitive case.

Description. Female (holotype): Prosoma length 5.1, prosoma width 4.2, anterior width of prosoma 2.5, opisthosoma length 6.3, opisthosoma width 3.0. Eyes including lenses and pigments absent. Spination: Palp: 131, 101, 2121, 1014; legs: femur I-III 323, IV 321; patella I-IV 000; tibia I-II 2126, III 2226, IV 22(1)26; metatarsus I-II 0004, III 2014, IV 2024. Ventral leg metatarsi with 5-7 short bristles distally, metatarsus IV additionally with double row of bristles along entire length. Leg formula: 2(14)3. Measurements of palp and legs: Palp 10.1 (2.9, 1.4, $2.5,-, 3.3)$, leg I $30.2(8.2,3.1,9.3,7.8,2.1)$, leg II $32.8(9.2,3.3,10.0,8.2,2.1)$, leg III $28.2(8.0,2.9,8.2,7.3,1.8)$, leg IV $30.2(8.5,2.7,8.5,8.4,2.1)$. Cheliceral furrow with 3 anterior and 4 posterior teeth (Fig. 80), and with 
restricted patch of 15-20 denticles close to anterior teeth. Margin of chelicerae close to fang base with one bristle. Palpal claw with 9 teeth. Sternum, ventral coxae and femora, distal legs as well as frontal chelicerae with long setae, otherwise with short setae.

Copulatory organ as in diagnosis (Figs 61-65). Epigynal field slightly wider than long, with two short anterior bands and one slit sensillum on each side close to the field. Lateral lobes fused, posteriorly bilobal. Epigynal pockets running from posterior-lateral to medio-anterior, where copulatory openings are situated. Glandular appendages short and narrow. Spermathecae bulging to the dorsal side, fertilisation ducts arising posterio-laterally, long and narrowly laminar. Sclerotised spheres present at posterior junction of lateral lobes.

Colouration in ethanol (Figs 78-80): Pale yellowish-brown without pattern. Dorsal prosoma with cephalic part slightly darker than thoracic part, fovea marked reddish-brown. Chelicerae, labium and gnathocoxae brown. Opisthosoma ventrally slightly darker. For colouration of live specimens see Figs. 76-77.

Male. Unknown.

Variation. Measurements female paratypes (n=3): PL 5.1-5.7, PW 4.2-4.8, AW 2.5-2.9, OL 5.8-8.0, OW 3.0-4.0. One juvenile with 1 proximal spine on dorsal metatarsus of palp (as in holotype of $S$. guap spec. nov.).

Distribution. Only known from the type locality (Fig. 81).

Biology. Spiders have been found only in one large crevice in a limestone massive so far and there exclusively in the aphotic zone. Usually ambushing or moving slowly, they escape quickly when disturbed. However, they are not as fast as species of the genus Heteropoda or other Sinopoda species from China for instance. At the cave entrance Heteropoda maxima and $H$. tetrica Thorell, 1897 occured.
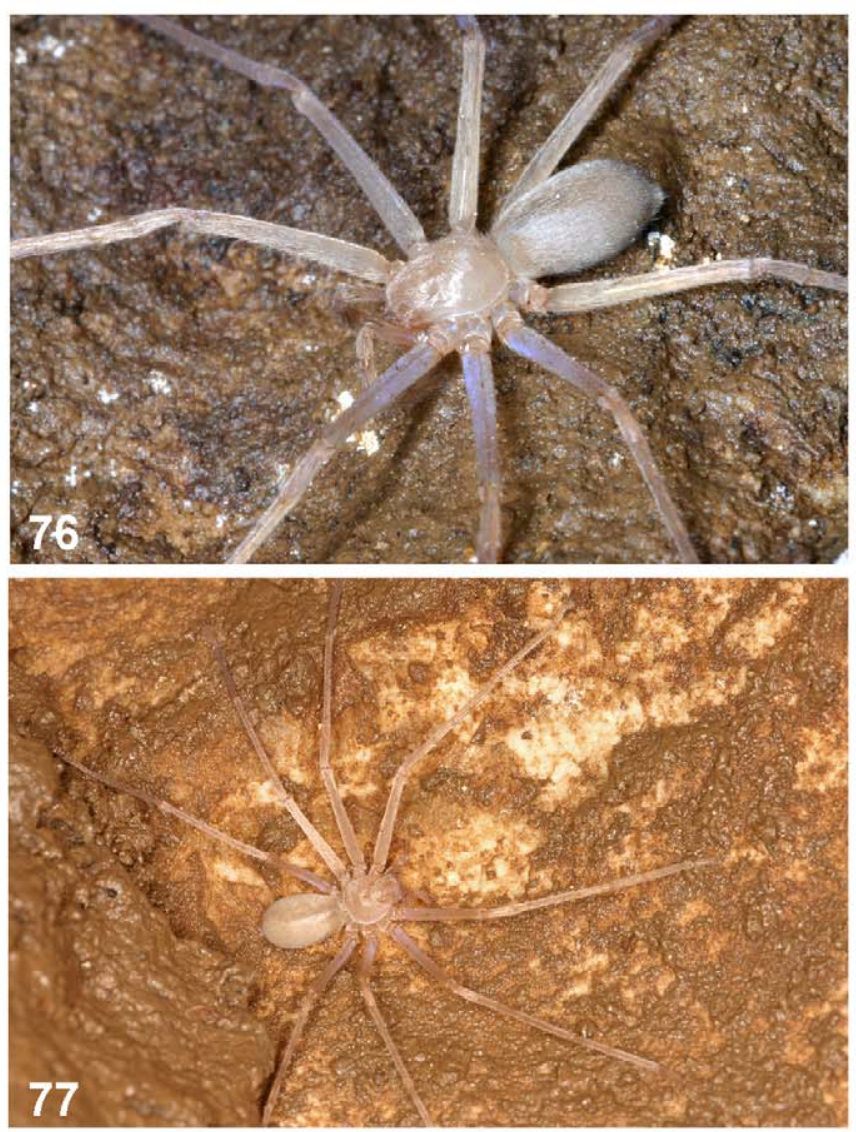
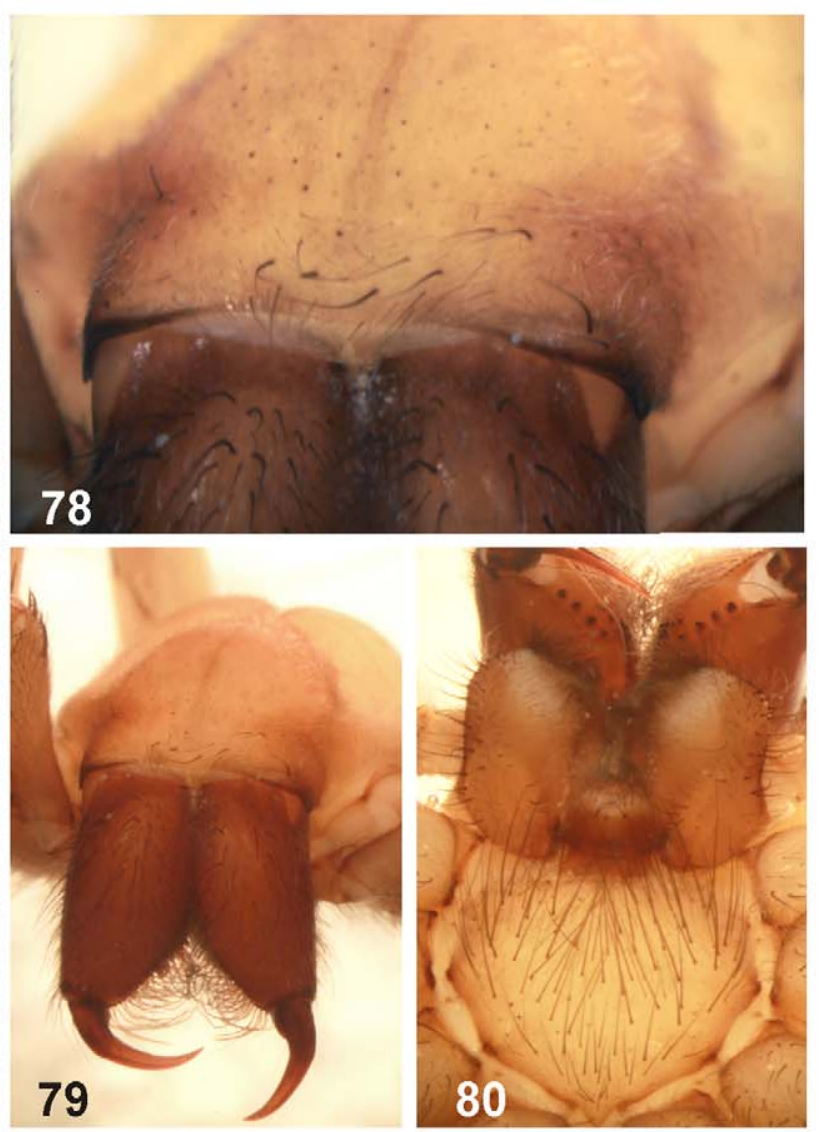

FIGURES 76-80. Sinopoda scurion spec. nov. holotype female from foot cave close to Thakek, Khammuan. 76-77 Habitus of live specimen. 78-79 Prosoma, frontal. 80 Prosoma, ventral.

\section{Immature specimens}

Although the following spiders could not be identified due to their immature stage, they are listed with their localities and with a short description of their eyes. Judging from experiences with adult females and their partly closely situated localities, all immature spiders listed here likely represent species on their own. 


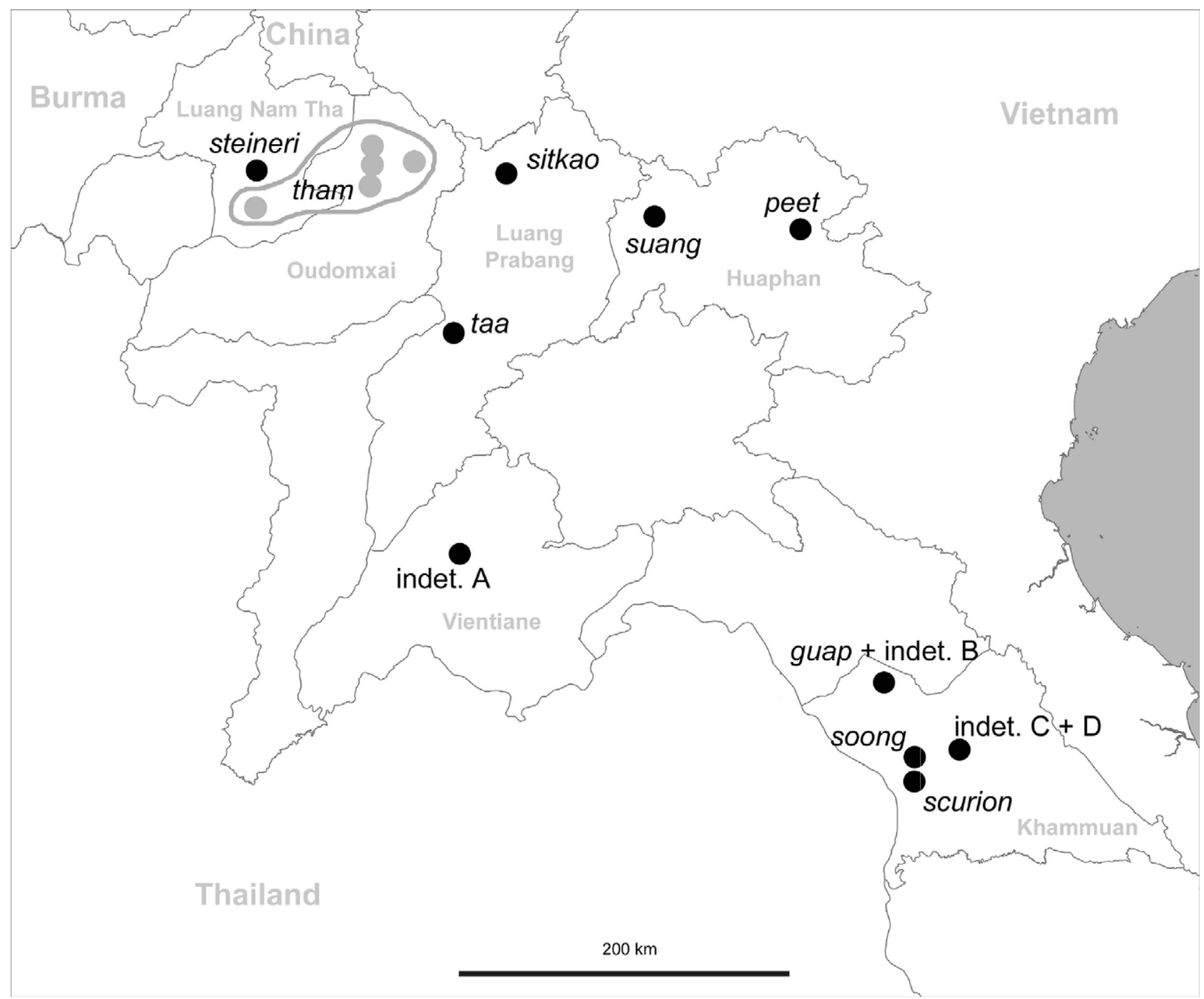

FIGURE 81. Records of Sinopoda spp. in Laos.

\section{Sinopoda sp. indet. A}

Fig. 81

Material examined. LAOS: Vientiane Province: 1 juvenile, Vang Vieng, Tham None [N 1856'47.19", E $102^{\circ} 26^{\prime} 2.84^{\prime \prime E}, 244 \mathrm{~m}$ altitude], in cave, by hand, 1 January 2000, Th.None V, Deharveng \& Bedos leg., field number LAO-111 (SMF).

The specimen is completely eyeless. Most likely and according to the restricted ranges of other known Sinopoda species, it might represent a species on its own different from S. scurion spec. nov. from Khammuan.

\section{Sinopoda sp. indet. B}

Fig. 81

Material examined. LAOS: Khammuan Province: 1 subadult female, Tham Nam Non, $25 \mathrm{~km}$ SE Na Hin, N18 $01^{\prime} 42.3^{\prime \prime}$, E104 $41^{\prime} 24.0^{\prime \prime}$, river cave in limestone, by hand, 18 February 2004, H. Steiner leg., field number 109/04 (SMF).

All eight eyes are present including pigments. However, the size of all eyes is strongly reduced especially in the tiny PME. From this character it seems unlikely that it is conspecific with $S$. guap spec. nov. recorded from the same cave. 


\section{Sinopoda sp. indet. C}

Fig. 81

Material examined. LAOS: Khammuan Province: 1 subadult male, Gnommalat, Ban Thatot, Grotte "Marie Cassan”, N17 $37.449^{\prime}, \mathrm{E} 105^{\circ} 08.809^{\prime}$, [180m altitude], cave in limestone, by hand, 24 February 2003, H. Steiner leg., field number 022/03 (SMF).

All eight eyes are present including remnants of pigments, thus it is most similar to Sinopoda sp. indet. B.

\section{Sinopoda sp. indet. D}

Fig. 81

Material examined. LAOS: Khammuan Province: 1 juvenile, Gnommalat, Ban Thatot, Tham Kamouk, entrance:

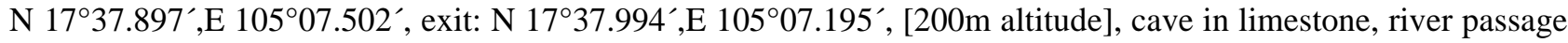
close to ceiling break down, aphotic zone, c. $25^{\circ} \mathrm{C}$, at day, by hand, 26 April 2012, P. Jäger \& L. Nophaseud leg. (SMF, SD 1203).

Four small eye lenses without pigments are present. Most likely the single juvenile belongs to a yet undescribed species.

\section{Acknowledgements}

I am grateful to colleagues who collected spiders in caves and sent this material for examination: $\mathrm{H}$. Steiner (Hanau), W. Zillig (Samerberg), L. Deharveng (Paris), and A. Bedos (Paris). At the same time I acknowledge the support for these latter colleagues by their respective expedition teams: French Khammuan Expedition team and Northern Lao-European Cave Project. Moreover, I thank persons accompanying me during my travels and helped with collecting spiders: L. Nophaseud (Vientiane), S. Kamphousao (Vientaine), S. Bayer (SMF), V. Vedel (Kourou), and F. Steinmetz (Berlin). Prof. B. Praxaysombath (National University, Vientiane) supported my projects in Laos. H. Steiner (Hanau) and D. Brandis (Kiel) provided useful comments and literature references. Thanks also to two anonymous referees and C. Muster for improving my manuscript.

\section{References}

Bayer, S. \& Jäger, P. (2009) Heteropoda species from limestone caves in Laos (Araneae: Sparassidae: Heteropodinae). Zootaxa, 2143, 1-23.

Davies, V.T. (1994) The huntsman spiders Heteropoda Latreille and Yiinthi gen. nov. (Araneae: Heteropodidae) in Australia. Memoirs of the Queensland Museum, 35, 75-122.

Dreybrodt, J. \& Laumanns, M. (eds.) (2005) The unknown North of Laos (Karst and caves of the provinces Luang Phrabang and Luang Nam Tha). Berliner Höhlenkundliche Berichte, 16, 1-105 + appendix.

Dreybrodt, J. \& Laumanns, M. (eds.) (2008) The unknown North of Laos (Part 2 - 2006-2008: Karst and caves of the provinces Luang Phrabang, Luang Nam Tha, Xieng Khouang, Houaphan and Vientiane). Berliner Höhlenkundliche Berichte, 32, $1-143$.

Dreybrodt, J. \& Laumanns, M. (eds.) (2010) The unknown North of Laos (Part 3 - 2009-2010: Karst and caves of the provinces Houaphan and Oudomxay). Berliner Höhlenkundliche Berichte, 38, 1-94 + appendix.

Dreybrodt, J. \& Laumanns, M. (eds.) (2011) The unknown North of Laos (Part 4 - 2011: Karst and caves of the provinces Oudomxay and Sayabouli). Berliner Höhlenkundliche Berichte, 44, 1-50 + appendix.

Jäger, P. (1998) An old-fashioned way to catch sparassid spiders. Newsletter of the British Arachnological Society, 82, 4.

Jäger, P. (1999) Sinopoda, a new genus of Heteropodinae (Araneae, Sparassidae) from Asia. The Journal of Arachnology, 27, $19-24$.

Jäger, P. (2001) Diversität der Riesenkrabbenspinnen im Himalaya. Über eine Radiation zweier Gattungen in den Schneetropen (Araneae: Sparassidae: Heteropodinae). Courier Forschungsinstitut Senckenberg, 232, 1-136.

Jäger, P. (2004) A study of the character 'palpal claw' in the spider subfamily Heteropodinae (Araneae: Sparassidae). In: Logunov, D.V. \& Penney, D. (Eds), Proceedings of the 21st European Colloquium of Arachnology, St.-Petersburg, 4-9 August 2003. KMK Scientifik Press, Moscow, pp. 107-125.

Kottelat, M. \& Steiner, H. (2010) Bangana musaei, a new cave fish from central Laos (Teleostei: Cyprinidae). Ichthyological 
Exploration of Freshwaters,21, 289-384.

Liu, J., Li S. \& Jäger, P. (2008) New cave-dwelling Sinopoda spiders (Araneae: Sparassidae) from southern China. Zootaxa, 1857, 1-20.

Lourenço, W.R. (2007) First record of the family Pseudochactidae Gromov (Chelicerata, Scorpiones) from Laos and new biogeographic evidence of a Pangaean palaeodistribution. Comptes Rendues Biologies, 330, $770-777$.

Lourenço, W.R. (2012) The genus Vietbocap Lourenço \& Pham, 2010 (Scopriones: Pseudochactidae); proposition of a new subfamily and description of a new species from Laos. Comptes Rendues Biologies, 335, 232-237.

Moradmand, M. \& Jäger, P. (2011) A review on the huntsman spider genus Spariolenus Simon 1880 (Araneae: Sparassidae: Heteropodinae) in Iran, with description of four new species. Zootaxa, 2910, 46-62.

Paquin, P. \& Dupérré, N. (2009) A first step towards the revision of Cicurina: redescription of type specimens of 60 troglobitic species of the subgenus Cicurella (Araneae: Dictynidae), and a first visual assessment of their distribution. Zootaxa, 2002, $1-67$.

Platnick, N.I. (2012) The world spider catalog, version 12.5. American Museum of Natural History. Available from: http:// research.amnh.org/iz/spiders/catalog/INTRO1.html [accessed 24 March 2012).

Yeo, D.Y.C \& Ng, P.K.L. (1999) Erebusa calobates, new genus, new species, a trogolobiotic crab (Brachyura: Potamidae) from Laos. Journal of Crustacean Biology, 19, 908-916.

Zhang, B.S., Zhu, M.S., Jäger, P. \& Song, D.X. (2007) A new species of the genus Sinopoda from China (Aranei: Sparassidae: Heteropodinae). Arthropoda Selecta, 15, 251-253. 